\title{
PROPERTIES AND MODIFICATION METHODS OF HALLOYSITE NANOTUBES: A STATE-OF-THE- ART REVIEW
}

\author{
MUHAMMAD JAWWAD SAIF, HAFIZ MUHAMMAD ASIF* AND MUHAMMAD NAVEED \\ Department of Applied Chemistry \& Biochemistry, Government College University, Allama Iqbal Road, Faisalabad 38000, Pakistan
}

\section{ABSTRACT}

The halloysite nanotubes (HNTs) are naturally found in New Zealand, China, Brazil, America, and France. Halloysite nanotubes have unique physical, chemical, and electrochemical properties. Due to their non-hazardous nature and easy availability, they are used in various fields of science. To improve halloysite nanotubes' interactions, these can be functionalized by different modification methods like covalent functionalization, non-covalent functionalization, etc. The chemical formula of halloysite nanotubes is $\mathrm{Al}_{2} \mathrm{Si}_{2} \mathrm{O}_{5}(\mathrm{OH})_{4} \cdot 2 \mathrm{H}_{2} \mathrm{O}$. HNTs have a nanotubular geometry which exhibit its dimensions on nanoscale. This nanotubular array of HNTs varies with different regions. In this review, we have tried to reiterate the key properties and various methods to modify halloysite nanotubes.

KEYWORDS: Halloysite occurrence; Halloysite chemistry; Functionalization of HNTs; Halloysite properties

\section{INTRODUCTION}

The chemical formula of halloysite nanotube aluminosilicate clay is $\mathrm{Al}_{2} \mathrm{Si}_{2} \mathrm{O}_{5}(\mathrm{OH})_{4} \cdot 2 \mathrm{H}_{2} \mathrm{O}$. The halloysite nanotubes (HNTs) are naturally found in New Zealand, China, Brazil, America, and France ${ }^{1}$. Over millions of years, HNTs are naturally formed in the earth by surface weathering of aluminosilicate clay mineral deposits. There are four elements which make the composition of halloysite Al, Si, H and O. HNTs is a fine clay mineral with nanotubular particles and manifold wall structure ${ }^{2}$.

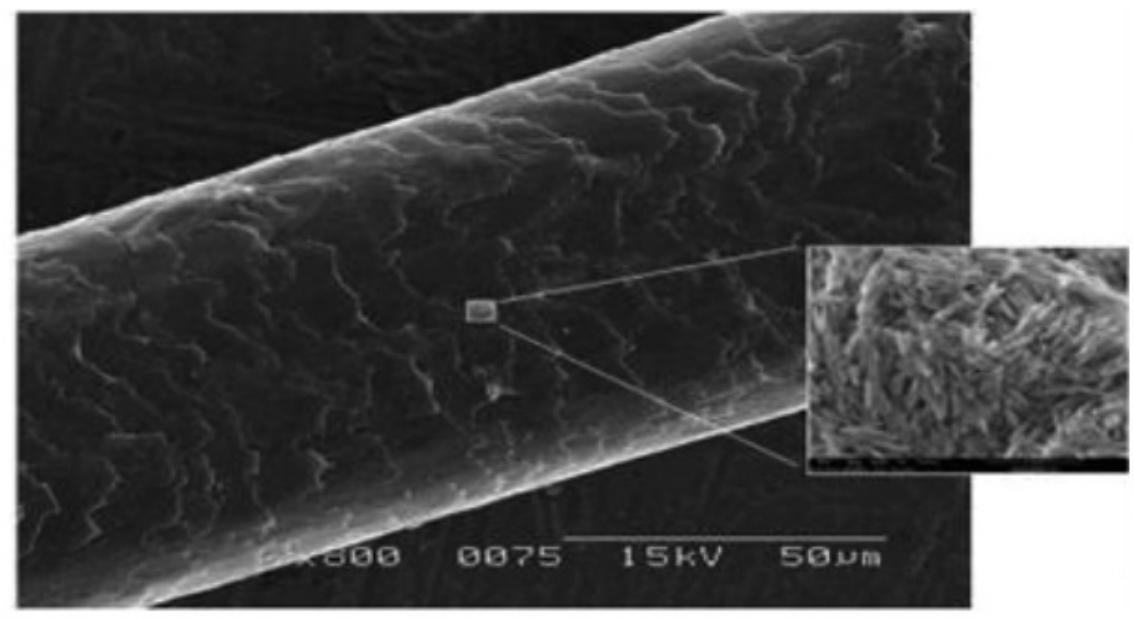

Fig- 1 HNTs compared with the width of human hair ${ }^{139}$

Literature reports that halloysite nanotubes have idiosyncratic dimensional morphology and which is formed by two basic building blocks; one is the tetrahedral and the second is octahedral ${ }^{3}$. In the octahedral sheet, simply twothirds of the existing octahedral puts is packed by aluminum. The crystalline configuration of halloysite is defined as 1:1 dioctahedral layers silicate ${ }^{4}$. The discrepancies in the symmetry of the ultimate configuration of halloysite are because of the water molecules present between two consecutive layers. Structurally a halloysite is tubular and chemical similar to stack and platy kaolinit of varying dimensions ${ }^{5,6}$.
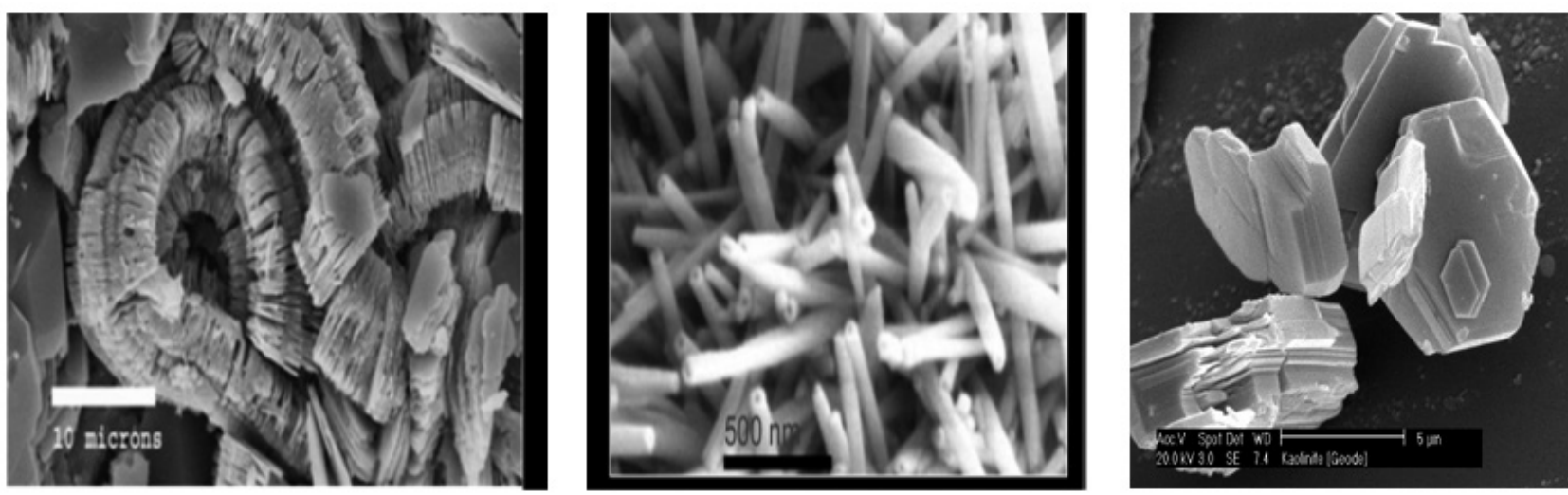

Fig- 2 Structural of halloysite and its chemical similar kaolinite ${ }^{6}$ 
The presence of tubular or cylindrical particles indicates halloysite on the other hand with platy particles are termed as kaolinite. Halloysite nanotubes are used as a template in nanotechnology ${ }^{7}$.

Polymer nanocomposites are a new class of materials in which nano-fillers are used as reinforcement and they show better physical and thermo-mechanical properties than conventional polymer nanocomposites ${ }^{8}$. Shi et al. observed the improvements in properties like stiffness, thermal, barrier, electrical properties, dimensional stability, toughness and fire retardant augmentations as compared to the bulk polymer ${ }^{9}$. The final performance of polymer nanocomposites depends upon the degree of dispersion of filler and its interactions with the polymer matrices ${ }^{10}$. Disperion state of the filler greatly influences the mechanical properties of nanocomposites. A homogeneous dispersion of filler results in enhanced mechanical performance whereas agglomerated particles lead to adversely affect the mechanical performance. Modified halloysite show improved compatibility and interactions with polymer matrices and hence a uniform dispersion can achieve. Literature suggests that the prope choice of material and design of process are of crucial importance to get the full benefits of HNTs as reinforcing nanofiller for polymer matrices. Methods of dispersion of nanoparticles in a polymer matrix have always remained under special consideration due to their agglomeration, which adversely reduces the performance of nanoparticles in the matrix. In case of HNTs, thei relatively large surface energy (due to large surface area $=\sim 60 \mathrm{~m}^{2} / \mathrm{g}$ ) causes their agglomeration owing to presence of van der Waals forces between tubes ${ }^{11}$. The conventional mixing methods such as ultrasonic dispersion methods and shear stresses like mechanical and magnetic bar stirring have proven to break agglomeration of HNTs to some extent. However, severe shear stresses like melt extrusion ${ }^{12}$ and ball mill homogenization ${ }^{13}$ methods may break agglomeration of HNTs to achieve fine homogeneous dispersion of HNTs in polymer matrices

Literature study reveals that surface modification of HNTs is a much better method to disperse them in polymer matrices as compared to conventional mixing methods. For example, the intercalation and exfoliation of organic or inorganic compounds in the layers of HNTs expanded their basal spacing and produced a homogenized dispersion of HNTs within polymer matrices under mixing ${ }^{14}$. Polymer grafting of HNTs via chemical process also proved a good method to get composites with homogenized disperse HNTs. For example, HNTs grafting with polyacrylonitrile (PAN) and polystyrene prepared by atom transfer radical polymerization (ATRP) ${ }^{15}$, HNTs grafting with PMMA and PVA/PMMA by radical polymerization ${ }^{16}$. Other chemical treatments involved treatment of HNTs with potassium acetate (PA), silane and cetyl trimethylammonium chloride (CTAC) were not found much suitable for intercalation of HNTs. However, results demonstrated that PA treatment is an effective treatment for reduction of HNTs particle cluster (agglomerates) size in epoxies and ultimately enhanced the mechanical properties ${ }^{13}$. Figure 3 shows the HNTs particle size distributions measured by a particle size analyzer. Dendritic polyamidoamine-grafted HNTs is found effectively improving interfacial interactions between HNTs and epoxy matrix and ultimately improving their dispersion in final epoxy nanocomposites imparting improve impact strength, modulus and fracture toughness ${ }^{17}$.

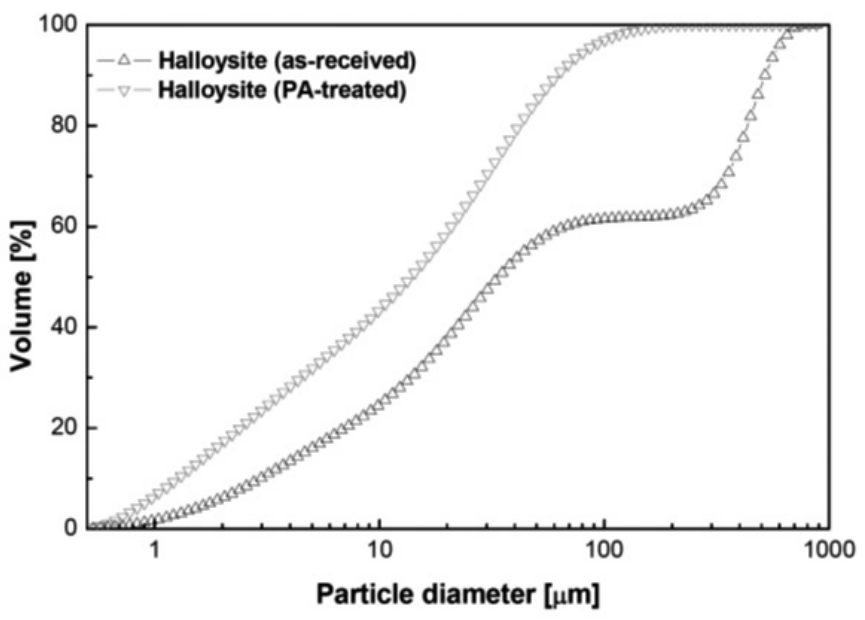

Fig- 3 Size distributions of as-received and PA-treated HNTs particles ${ }^{13}$

In another study, marvelous improvement was observed in the dispersion of PPA treated HNTs in epoxy matrix ${ }^{18}$. PPA treatment of HNTs changed the structural morphology of HNTs from nano-tube to nano-platelet, which created additional particle surface due to the unfolding of nanotubes provided release of the internal surface area as seen in Figure 4. This increased contact surface could provide more active sites for interaction of HNTs with epoxy matrix and thus increased fracture toughness of the nanocomposites was achieved as compared to the composites with pristine HNTs and even modified HNTs using the mechanical mixing treatments.
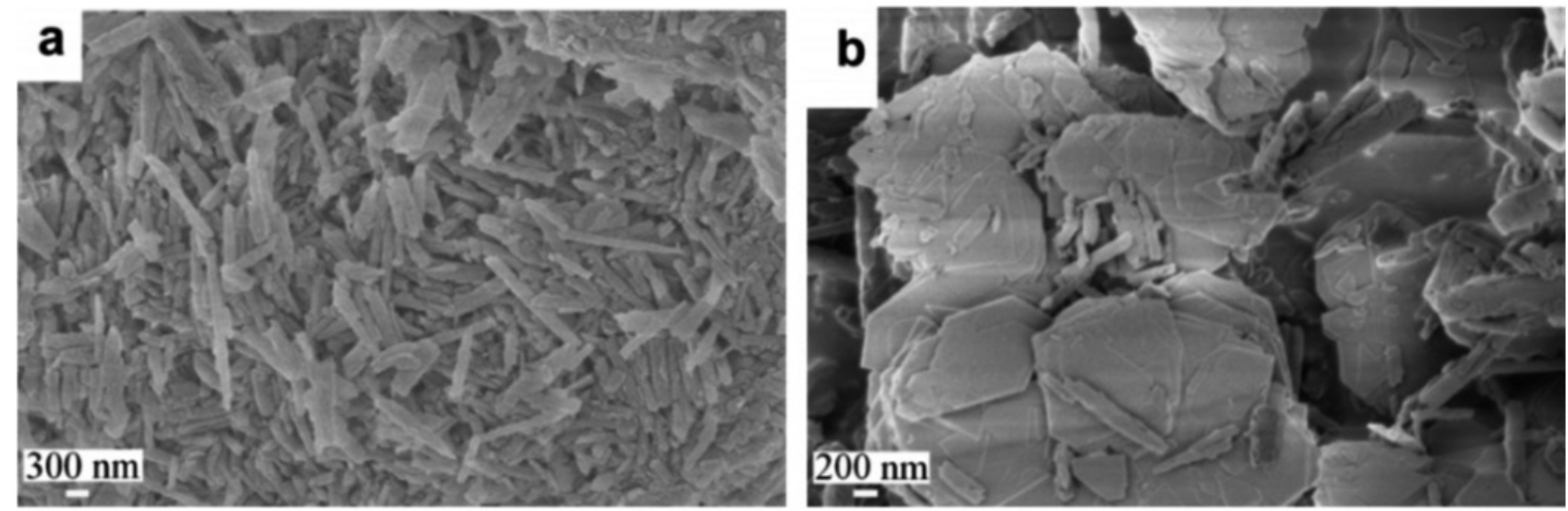

Fig- 4 SEM photographs of (a) pristine HNTs and (b) 100 h-PPA-modified HNTs ${ }^{18}$ 
Hári et al. reported that a number of reinforcements can be used to reinforce the thermoplastics matrices. Polypropylene (PP) is an essential plastic, which is being broadly used for the manufacturing of domestic articles and automotive industrial spare parts. By upgrading the mechanical performance of polypropylene, its applications in different industrial zones can be expanded 19. That's why PP has been used as a common polymer matrix in making the composites by the incorporation of fillers such as carbon nanotubes (CNTs), montmorillonites (MMTs) and nanoparticles including silica, graphite and calcium carbonate, although the dispersion of fillers is a challenging issue ${ }^{20}$. The high stiffness value of MMTs makes the composite with the higher value of strength and modulus ${ }^{21}$.

Bascom et al. reported that owing to the properties like good adhesive strength, high stiffness and hardness, good heat and chemical resistance, epoxies have a wide range of applications. But many of the epoxy systems after curing show poor fracture toughness, less resistance to crack initiation and propagations, and low impact strength ${ }^{22}$. The fracture toughness of the epoxy systems can be improved by the incorporation of fillers into the epoxy matrix with the reduction in some basic properties ${ }^{23}$.

Kinloch and Taylor made many efforts to modify the epoxies with rigid nanoparticles or nanofibers to make epoxy composites with distinctive properties better than traditional polymer nanocomposites ${ }^{24}$. MMTs particles have been extensively studied as a modifiers for improving the performance of epoxy resins specifically in term of fracture toughness ${ }^{25}$. Inorganic additives, such as silica, alumina and glass particles, have been found to be promising modifiers for increasing the fracture toughness of epoxies without sacrificing their basic properties ${ }^{26}$

Gojny et al. reported the carbon nanotubes to be an ideal filler to modify the polymers. A number of efforts have been made in manufacturing CNTs/ epoxy composites but the cost is a big issue ${ }^{27}$. Newly, HNTs due to their unique properties is considered good filler for polymers to form their composites having a better coefficient of thermal expansion (CTE) and modulus ${ }^{28}$. Kubade and Tambe prepared HNTs filled acrylonitrile butadiene styrene/polypropylene blends and its composites with and without using dual compatibilizer (maleic anhydride grafting with polypropylene (PP-g-MA), and maleic anhydrite grafting with styrene-ethylene/butylene-styrene triblock copolymer (SEBS-gMA)). Considerable refinement in homogenized ABS droplets diameter and the interparticle distance between dispersed ABS droplets were investigated in case of halloysite incorporated 20/80 (wt/wt) ABS/PP blend and its composites using SEBS-g-MA and PP-g-MA. A remarkable improvement in impact and tensile strength of HNTs incorporated 20/80 (wt/wt) ABS/PP blend and its composites using SEBS-g-MA and PP-g-MA ${ }^{29}$. Saheb et al. prepared HNTs and intumescent flame retardant (IFR)-incorporated $20 / 80$ by weight ABS/ PP blend and its composites using dual compatibilizer. The enrichment of crystallinity of PP phase was observed owing to formation of $\alpha$ - and $\beta$-form of PP crystals and advantageously using HNTs and IFR in 20/80 (wt/wt) ABS/PP blend and it composites using dual compatibilizer. Thermal stability was also improved ${ }^{30}$. In another study ABS/PP blends and its composites in presence of dual compatibilizer were prepared. The used fillers were Halloysite, carbon black and intercalated graphite. The tensile modulus and impact strength was increased significantly. Thermal stability was increased for hybrid fillers reinforced $\mathrm{ABS} / \mathrm{PP}$ blends using dual compatibilizer in comparison to neat blends ${ }^{31}$.

Halloysite is appeared to be low priced, interesting and ideal nanofillers for the preparation of polymer composites. A large number of publications were reported regarding various properties of halloysite/polymer composites ${ }^{21}$. HNTs reinforced nanocomposites, nanotubes, nanopowders, etc. now are escalating fashion setters in olive nanotechnology. Halloysite nanotubes are ecofriendly and environmental benign material with the advantage of their easy availability and low cost as compared to carbon nanotubes.

\section{HALLOYSITE: CHARACTERISTICS}

\subsection{Physical properties of halloysite nanotubes}

In research studies, the specifications of halloysite nanotubes used are given in table 1.
Table- 1: Physical properties of halloysite nanotubes ${ }^{128}$

\begin{tabular}{|c|c|}
\hline Physical property & Value \\
\hline HNTs characteristic surface area & $65 \mathrm{~m}^{2} / \mathrm{g}$ \\
\hline HNTs aperture volume & $1.25 \mathrm{~mL} / \mathrm{g}$ \\
\hline Halloysite specific gravity & $2.53 \mathrm{~g} / \mathrm{cm}^{3}$ \\
\hline Refractive index of halloysite & 1.54 \\
\hline HNTs internal lumen diameter & $15 \mathrm{~nm}$ \\
\hline HNTs mean tube diameter & $50 \mathrm{~nm}$ \\
\hline
\end{tabular}

1. The surface of HNTs is negatively charged like silica $\left(\mathrm{SiO}_{2}\right)$ surface at $6-7 \mathrm{pH}$ while halloysite nanotube's internal core is positively charged and correlated to alumina $\left(\mathrm{Al}_{2} \mathrm{O}_{3}\right)$.

2. The positively charged halloysite nanotube's internal core supports the loading of negatively charged bigger molecules into the empty spaces of its lumen, and at the same time, these negatively charged macromolecules are repelled by the negatively charged external surface ${ }^{129}$. Halloysite is non-toxic for cells and those with external diameter of 50 to $70 \mathrm{~nm}$, diameter lumen of $15 \mathrm{~nm}$ and length of 0.5 to $1 \mu \mathrm{m}$ in are chemically stable ${ }^{32,33}$. The halloysite nanotubes are characterized by transmission electron microscopy (TEM), scanning force microscopy (SFM) and scanning electron microscopy (SEM). The most part of the HNT's morphology is made of of cylindrical tubules of $40-50 \mathrm{~nm}$ diameter and $0.5-2 \mu \mathrm{m}$ in length. HNTs are polydispersed particularly regarding length. Transmission electron microscopy (TEM) verifies the existence of hollow lumen of HNTs with diameter of $15-20 \mathrm{~nm}$. HNTs are comparatively less flexible as compared to carbon nanotubes which have Young's modulus approximately of $1 \mathrm{TPa}{ }^{34}$. SEM and TEM (figure- 5) analysis showed that it consist mainly of hollow microtubules with a typical dimension of 0.08-0.20 $\mu \mathrm{m}$ diameter and lengths of 0.50-4.50 $\mu \mathrm{m}$.

2.2 Chemistry

HNTs and kaolin are chemically interrelated to each other. There are two types of hydroxyl groups holding halloysite nanotubes, one is the inner hydroxyl groups and second are the outer ${ }^{-} \mathrm{OH}$ groups. Inner ${ }^{-} \mathrm{OH}$ groups are present inside of the lumen and the outer ${ }^{-} \mathrm{OH}$ groups are located on the edges and corner of tubes ${ }^{130}$. The silica $\left(\mathrm{SiO}_{2}\right)$ and siloxane groups are essentially existing on the surface of halloysite ${ }^{35}$. Single walled and multi-walled HNTs are used in the field of nanotechnology ${ }^{36}$.

2.3 Solubility and stability of halloysite

In a study of the supramolecular adduct of HNTs and deoxyribonucleic acid (DNA), it is reported that halloysite is stable molecules towards acidic, basic aqueous suspension and also stable at normal temperature and in pure water ${ }^{37}$. Mohtashim and Kurt studied that in $1 \mathrm{M}$ sulfuric acid $\left(\mathrm{H}_{2} \mathrm{SO}_{4}\right)$ solution, the halloysite nanotubes start to dissolve from the inner surfaces of halloysite nanotubes, and as a result amorphous spheroidal nanoparticles of silica $\left(\mathrm{SiO}_{2}\right)$ are formed, whereas, in $1 \mathrm{M}$ sodium hydroxide $(\mathrm{NaOH})$ solution, the halloysite nanotubes start to dissolve from inner surface but results in the formation of aluminium hydroxide $\left(\mathrm{Al}(\mathrm{OH})_{3}\right)^{38}$. Current study findings suggest that halloysite are nontoxic and chemically are stable for the cells having outer diameter of 50 to $70 \mathrm{~nm}$, inner lumen diameter of $15 \mathrm{~nm}$ and length of 1 to $0.5 \mu \mathrm{m}^{39}$

\subsection{Halloysite advantages}

The following are the advantages of halloysite:

Halloysite is naturally occurring, innocuous, biocompatible and environmental protection agency (EPA 4A) listed nanomaterials. Halloysite has a fine particle size, larger surface area and excellent dispersion property in the matrix. The cation exchange power of halloysite is high. Halloysite keeps homogeneousness, and give tenacious release rates and no requisite for primary over dose. HNTs are able of prohibiting discharge unless triggered and tunable discharge rates are obtained. Within the inner lumen of halloysite, the active particles are secluded through the processing of callous material. Halloysite supports to load a large number of active particles at once. Halloysite lessens the size of costly active particles. Halloysite can be used in various ways like creams, in the form of powders, in the form of gels, sprays, and lotions. Higher charging rates comparatively to former carriers, fast adsorption rates, and superior adsorption competency make them ideal. Halloysite nanotubes have high aspect quotient, enormous pores, and non-swelling nature. Halloysite has regenerating capability and augmented efficacy. 


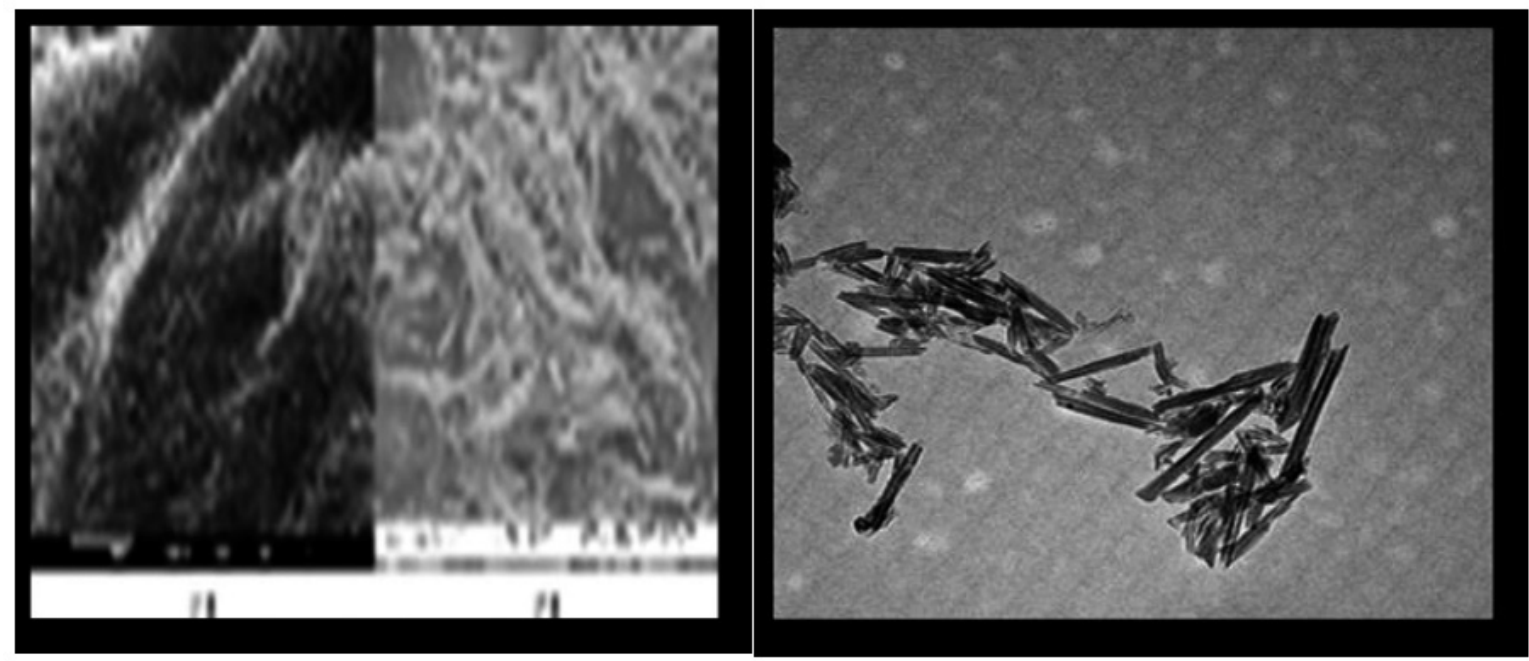

Fig- 5 SEM and TEM image of HNTs ${ }^{139}$

\subsection{Tubular structure}

It has been described that typically high aspect ratio of halloysite nanotubes and nanotubular structure help the reinforcement of halloysite in polymer composites and as a resultant, optimized load is shifted from the matrix phase to reinforcement. In addition to this halloysite nanotubes have the elastic modulus of $140 \mathrm{GPa}^{40-42}$. Liu et al. reported the particle size of halloysite nanotubes may range from 50 to $400 \mathrm{~nm}$ but in a $5 \mathrm{wt} . \%$ aqueous solution the average particle size is $143 \mathrm{~nm}{ }^{43}$. Brunauer, Emmett and Teller (BET) surface area value of halloysite nanotubes is moderate comparatively to other nanoparticles that is $\left(22.10 \text { to } 81.59 \mathrm{~m}^{2} / \mathrm{g}\right)^{44}$. It is reported that the lumen space of halloysite nanotubes is $10.7-39 \%$, so the density of halloysite nanotubes are comparatively lower $\left(2.14-2.59 \mathrm{~g} / \mathrm{cm}^{3}\right)^{21,45}$ comparatively to other fillers like talc and calcite, but comparable to montmorillonites and kaolinite. So light weight polymers composites can be made by the incorporation of HNTs It is cited that perfect microtubular structure of HNTs makes them ideal for loading of chemical and biologically active substances into the lumen. Many of the drugs like khellin, tetracycline and nicotinamide adenine dinucleotide have been charged within the lumen of halloysite nanotubes by sopping in a saturated solution of drug using vacuum suction ${ }^{46}$. The drug discharge time is increased from thirty to a hundred times more than the drug alone or in other carriers. By the addition of polymer layer to drug loaded halloysite nanotube surface, the drug discharge further slows down. Reactants can be loaded into the lumen of HNTs so these can be used as nanoscale reactors. Shchukin et al. used halloysite as vacant biological catalytic nanoreactors ${ }^{33}$. The uneasecatalyzed synthesis of $\mathrm{CaCO}_{3}$ entirely packed the internal halloysite lumen; no $\mathrm{CaCO}_{3}$ was produced on the external surface of the halloysite or in solution. Polymer chains or decomposition products also can entrap into the lumen of halloysite nanotubes as a result, the thermal stability and flame retardency is increased, so the degradation is slowed.

\subsection{Relative hydrophobicity}

Different research findings reveal that mostly the aluminols are located inside the halloysite nanotubes whereas the exterior surface of the halloysite nanotube is poised of siloxane groups, while some aluminols /silanols present on the edges of the sheets. Low contents of hydroxyl groups on the surface of HNTs make them hydrophobic comparatively to other nanoclays, so in non-polar polymers, HNTs can be readily dispersed ${ }^{47-50}$. This norma hydrophobicity of halloysite nanotubes is not enough for their dispersion in nanocomposite systems so these are extra treated to optimize their interfacialinteractions.

\subsection{Low tube-tube interactions}

It is studied that due to high surface activities nano particles tend to attach with one another for example, carbon nanotubes have strong attractions between nanotubes and making their dispersion challenging ${ }^{51}$. HNTs relatively have few tube- tube interactions comparatively to carbon nanotubes due to limited $-\mathrm{OH}$ groups present at the halloysite nanotube surface, indicating that the intertube interfacial bondings are comparatively weak and tube like structures with an appropriate aspect ratio create limited chances for larger contact area among nanotubes. So a uniform structure is commonly achieved in case of halloysite nanotube-polymer composites ${ }^{52}$.

\subsection{Reinforcement}

Because of high aspect ratio and nanoscale sizes, halloysite nanotubes are outstanding filler nano materials for various polymers. The polymer strength, stiffness, modulus and polymer impact resistance can be increased concurrently by halloysite. Moreover, by the incorporation of halloysite the mechanical performance of polymers at elevated temperatures can be improved, under both static and dynamic conditions.

\subsection{Flame retardency}

Du et al. studied the use of halloysite nanotubes as flame retardants (halogen free) in polymer composites owing to their barriers like nature contrary to heat and mass transport while sweltering the composites, the lumen of HNTs also act as a sink for polymer decomposition products. Additionally, traces of iron $(\mathrm{Fe})$ in halloysite also reduce the flammability of composites ${ }^{53}$. The char formation in case of a few polymeric systems, such as polycarbonate (PC) and acrylonitrile butadiene styrene rubber (ABS/PC) blend also attributed to HNTs surface acidity ${ }^{54,55}$. It is reported that structural water release temperature of HNTs is high $\left(400-600^{\circ} \mathrm{C}\right)^{11}$, indicating that halloysite nanotubes are fit for the polymers treated at comparatively higher temperatures. Halloysite may also be used as a flame resistant in polybutylene terephthalate (PBT), polyamide 6 (PA6), polyethylene terephthalate (PET), linear low density polyethylene (LLDPE) and polypropylene (PP).

\subsection{Distribution of hydroxyl groups}

Yah et al. studied that because of presence of aluminium in lumen and silica at the external surface of $\mathrm{HNTs}$, choosy modification of $\mathrm{SiO}_{2}$ and $\mathrm{Al}_{2} \mathrm{O}$ in halloysite nanotubes can be done via consecutive reactions exteriorly with silylating agents and interiorly with phosphonic acid. This bifunctionalization of halloysite nanotubes produces a different form of the adsorbent exhibiting tailor made properties. The hydrophobic and neutral molecules are encapsulated in the hydrophobic lumen by apportioning with a polar solvent, however, the dispersal of halloysite nanotubes in $\mathrm{H}_{2} \mathrm{O}$ is stabilized by solid polar shell that remain holding the lodger particles ${ }^{56}$.

2.11 Negative charge on the surface

Lvov et al. described that the surface charges of halloysite nanotubes are primarily negative enhancing their electrostatic attraction with cationic polymers. The layer-by-layer assemblage of halloysite nanotubes and polyetherimide (PEI) is used for the fabrication of HNTs-PEI nanocomposite 7. The chitosan (positively charged) polymer molecules can interact electrostatically with halloysite nanotubes for composite formation ${ }^{58}$.

\subsection{Electrophilicity}

Various studies show that aluminum species are the electrophilic sites on the HNTs at the crystal ends and the d-group elements (transition metals) in the higher valences of the silicate layers. It is also reported that halloysite can receive electrons to promote the polymerization reaction of some unsaturated organic species such as styrene, and hydroxyethyl methacrylate ${ }^{59}$. The electrophilic character of halloysite is beneficial to improve the interfacial interactions in polymer composites ${ }^{60}$.

\subsection{Porosity and surface defects}

Literature exposes that halloysite nanotubes have regular tubular structures and are rich mesoporous having pore space $14-46.8 \%$. So nanospace of HNTs 
can be packed or its surface is layered with various polymers. HNTs templates can be used for mesoporous carbon. HNTs templates offer two advantages ${ }^{61}$ : first the tube diameter is in nanometers, which promotes the permeation of the carbon source into halloysite nanotubes matrix; secondly halloysite nanotubes is a naturally occurring mineral, decreasing the rate of templated mesoporous carbon.

2.14 Abundance, easy availability and cheaper

Literature reports the halloysite nanotubes as green materials and nonhazardous to the environment. Main deposits of HNTs are found in countries like America, China, Brazil, Spain, France, New Zealand and others ${ }^{62,63}$. HNTs are a good substitute for applications where cost sensitivity is a concern. HNT's less cost and high enactment assist the development of halloysitepolymer composites.

\section{FUNCTIONALIZATION OF HALLOYSITE NANOTUBES}

For the optimized properties of nanocomposites, it is important to optimize the nanotube dispersion and stress transfer. The interfacial interaction between nanotubes and polymer must be carefully control. So functionalization of HNTs is particularly essential for processing and facilitating the properties of halloysite nanotubes-polymer composites. Modified nanotubes showed superior thermal-mechanical behavior. Functionalization mends the dispersal and stress-strain transfer. For this purpose the discussed methods are:

3.1 Decontamination of HNTs

The impurities like quartz, kaolinite, feldspar, perlite, illite and metal ions present in raw halloysite must be unglued and the aggregate tubes must be separate before their use. It is reported that the dispersion-centrifugationdrying technique based purification methods are used for HNTs $33,60,64$.

Various researchers reported that in a common routine a $10 \mathrm{wt} . \%$ aqueous suspension is developed by gradual addition of HNTs to distilled water at constant stirring. This suspension is heated at $60^{\circ} \mathrm{C}$ under stirring for 12 hours. Centrifugation is used for the separation of resulting product, then washed by distilled water three times and finally dried at $60{ }^{\circ} \mathrm{C}$ for $12 \mathrm{~h}$ in air. HNTs are filtered to remove any aggregation formed in drying step. Tween 80 and Sodium hexametaphosphate can be added to enhance the durability of HNTs in water and HNTs individualization ${ }^{60,64}$. Ames and Garcia et al. reported that almost pure HNTs deposits are found in Utah, USA ${ }^{65,66}$ which can be used without purification.

\subsection{Covalent functionalization}

Poikelispaa et al. reported that chemical species can be covalently attached to hydroxyl groups present on the interior surface and on edges of the sheets of multiwall nanotubes. Following changes may occur ${ }^{67}$ :

- Surface polarity of halloysite nanotubes can be minimized.

- Surface hydroxyl groups can be protected.

- Surface chemistry can be altered to incorporate compounds of carbon and hydrogen.

- Some useful groups can be generated on the surface.

It is reported that the dispersal of halloysite nanotubes in solvents and polymers is improved via enhancing their interfacial interactions.

3.2.1 Modification of halloysite nanotubes with 2-hydroxybenzoic acid 68

Li et al. reported the modification of HNTs with 2-hydroxybenzoic acid (HBA). $2.8 \mathrm{~g}$ amount of HBA was dissolved in $100 \mathrm{~mL}$ absolute ethanol, and $4.5 \mathrm{~g}$ of HNTs-3-Aminopropyltriethoxysilane (APTES) was suspended in the mixture under stirring and heating, then $4 \mathrm{~g}$ of $\mathrm{N}, \mathrm{N}^{\prime}$-dicyclohexylcarbodiimide (DCC) was added into the suspension and refluxed at $86^{\circ} \mathrm{C}$ for $48 \mathrm{~h}$. The product was filtered off, washed three times with absolute ethanol and dried in an oven at $60^{\circ} \mathrm{C}$ for $12 \mathrm{~h}$.
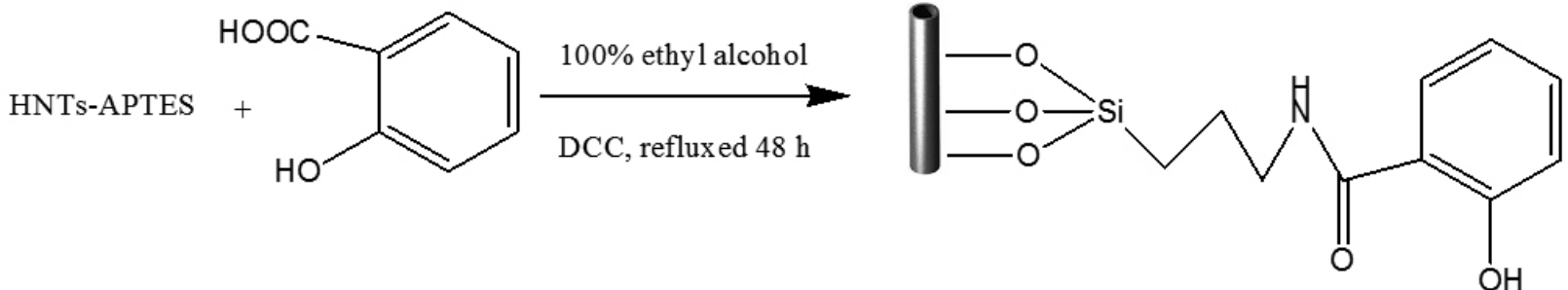

HNTs-HBA

Fig- 6 Halloysite nanotube modification with 2- hydroxybenzoic acid ${ }^{68}$

3.2.2 Modification of halloysite nanotubes with 2-bromoisobutyric acid ${ }^{69}$.

$\mathrm{Mu}$ et al. reported the modification of HNTs with 2-bromoisobutyric acid. $50 \mathrm{ml}$ of halloysite nanotubes suspension containing $0.5 \mathrm{~g}$ of HNTs were added into a $100 \mathrm{ml}$ flask. After that $5 \mathrm{ml}$ of ammonia solution in water having $\mathrm{pH} 7-8$ with $0.5 \mathrm{~g}$ of 2-bromoisobutyric acid was poured into $100 \mathrm{ml}$ flask. Then this mixture was agitated for $5 \mathrm{~h}$ to attain the absorption balance. The 2-bromoisobutyric acid amended HNTs (HNTs-Br) were detached by centrifugation at a rate of $12,000 \mathrm{rpm}$ for ten minutes. The modified halloysite nanotubes were kept for drying under vacuum at $50{ }^{\circ} \mathrm{C}$ temperature for $24 \mathrm{~h}$.

3.2.3 Modification of halloysite nanotubes with glycidyl methacrylate

Pasbakhsh et al. used glycidyl methacrylate (GMA) to modify halloysite nanotubes. One gram of purified halloysite nanotubes was grounded to a fine powder and then $40 \mathrm{ml}$ of toluene and $0.25 \mathrm{ml}$ of GMA were added into the powder. The prepared suspension was ultra-sonicated for $30 \mathrm{~min}$. The entrapped air from the lumen of halloysite nanotubes was removed by the vacuum pump. Then at constant stirring, the prepared suspension was heated at $80{ }^{\circ} \mathrm{C}$ temperature for $2 \mathrm{~h}$. Silica gel was used for the removal of extra air during heating. After centrifugation, the modified halloysite was extensively washed with fresh toluene 6 times. Then halloysite was dried in an oven at 105 ${ }^{\circ} \mathrm{C}$ temperature overnight.

3.2.4 Modification of halloysite nanotubes by plasma treatment ${ }^{7}$.

Poikelispaa et al. reported the surface modification of HNTs by plasma polymerization. The purpose of plasma treatment was to increase the rubberHNTs interactions and the dispersal of the HNTs. Two monomers one thiophene and second pyrrole were used for HNTs modification through plasma treatment. It was reported that thiophene modified halloysite showed better stress-strain properties than a pyrrole modified halloysite. In table 2 conditions for plasma treatment for thiophene and pyrrole monomers are given. Scanning electron microscopy (SEM) measurements showed an improved compatibility of elastomers and fillers.

Table-2: Parameters of plasma treatment ${ }^{71}$

\begin{tabular}{|c|c|c|c|c|}
\hline Monomers & $\begin{array}{c}\text { Pressure } \\
(\mathrm{Pa})\end{array}$ & $\begin{array}{c}\text { Monomer } \\
\text { pressure } \\
(\mathrm{Pa})\end{array}$ & $\begin{array}{c}\text { Power } \\
(\mathrm{W})\end{array}$ & $\begin{array}{c}\text { Time } \\
(\mathrm{min})\end{array}$ \\
\hline Pyrrole (Py-90) & 10 & 32 & 150 & 90 \\
\hline Thiophene (Thi-90) & 10 & 50 & 150 & 90 \\
\hline
\end{tabular}

\subsubsection{Silane coupling}

The commonly used covalent modification of halloysite nanotubes is to graft silane through condensation ${ }^{72}$. The inner surface modification is usually done for immobilization and organized discharge practices, however the exterior surfaces and boundaries are modified for its uses in composite formations. These reactions can proceed in toluene and water/alcohol mixtures. A number of researchers reported different silanes used for grafting onto HNTs are:

- $\quad \gamma$-Glycidoxy-propyltrimethoxysilane (GPTS) ${ }^{73,74}$

- 3- Amino-propyltrimethoxysilane (APS) ${ }^{15,75,131}$

- $\quad 3$ - Aminopropyltriethoxysilane (APTES) ${ }^{72,76,132-134}$

- [3-(2-Aminoethylamino)propyl] trimethoxysilane (AEAPS) ${ }^{56,77,135}$

- $\quad 3$-(Trimethoxysilyl) propyl methacrylate (MAPTS) ${ }^{78,79,136}$ 
- $\quad$ Vinyltrimethoxysilane (VTMS) ${ }^{80,137}$

- $\quad \gamma$-Methacryloxypropyl trimethoxysilane (MPS) ${ }^{138}$

$\gamma$ - Glycidoxypropyltrimethoxysilane (GPTS) and 3-(Trimethoxysilyl) propylmethacrylate (MAPTS) have been grafted onto halloysite nanotubes to improve the interfacial adhesion of the halloysite-polymer composites ${ }^{73}$. The pore analysis and X-ray photoelectron spectroscopy (XPS) also verified the grafting of silane onto halloysite nanotubes. By employing diffuse reflectance infrared fourier transform spectroscopy (DRIFTS), the silane grafting onto halloysite nanotubes can be predicted ${ }^{72,78}$. Figure- 7 showed the preparation of halloysite- $\mathrm{COOH}$, the halloysite nanotubes were initially functionalized with amino groups by grafting 3- Aminopropyltriethoxysilane (APTES) and then amino modified product (HNTs- $\mathrm{NH}_{2}$ ) was stirred with succinic anhydride by using dimethyl formamide (DMF) as solvent at constant stirring to generate HNTs-COOH ${ }^{81}$.

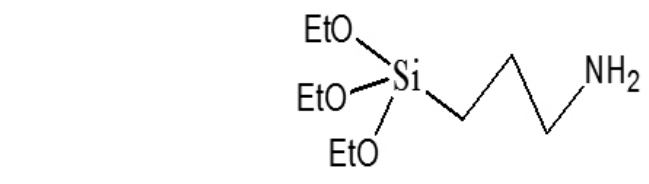

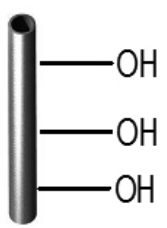

1)

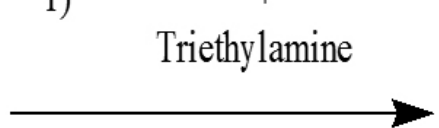

HNTs
2)

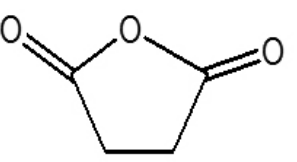

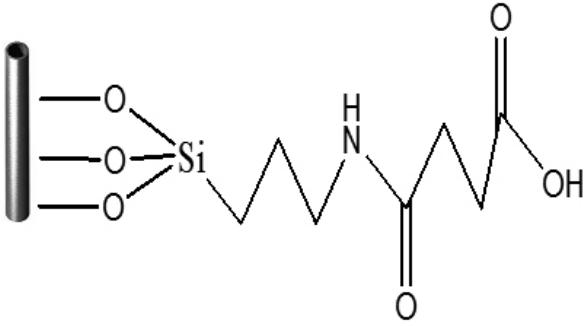

HNTs-COOH

Fig- 7 Preparation of $\mathrm{HNTs}-\mathrm{COOH}^{81}$

3.2.6 Surface graft polymerization

Various research groups reported the surface graft polymerization for modification of HNTs. Polymers can be grafted onto halloysite nanotubes such as the grafting of polybutylenes adipate (PBA) chains from $-\mathrm{OH}$ groups on the halloysite nanotubes surfaces can be do in double steps ${ }^{82}$ The halloysite grafted with PBA can increase the interfacial bond across the halloysite and the polyvinylchloride (PVC). Polymethylmethacrylate (PMMA) was grafted on halloysite nanotubes through in situ free radica polymerization ${ }^{79,83}$. Atom transfer radical polymerization (ATRP) is used for surface modification of halloysite nanotubes or for the direct preparation of HNTs-polymer nanocomposites 15, 75, 84. Polyacrylonitrile (PAN) and polystyrene (PS) were grafted on halloysite producing composites nanotubules. Alternative halloysite-polymer composite was synthesized via in situ pyrrole oxidative polymerization ${ }^{85}$. In same way, PMMA can be grafted onto halloysite nanotubes ${ }^{84}$. Plasma polymerization procedure can be used to alter the characteristics of halloysite. The plasma-treated halloysite showed better dispersal as a reinforcement in natural rubber (NR)-butadiene rubber blend.<smiles>OC(O)O</smiles>

HNTs<smiles>COC(=O)CCCCC(=O)OC</smiles><smiles>CCCCO</smiles>

Fig- 8 PBA grafted halloysite nanotubes ${ }^{82}$

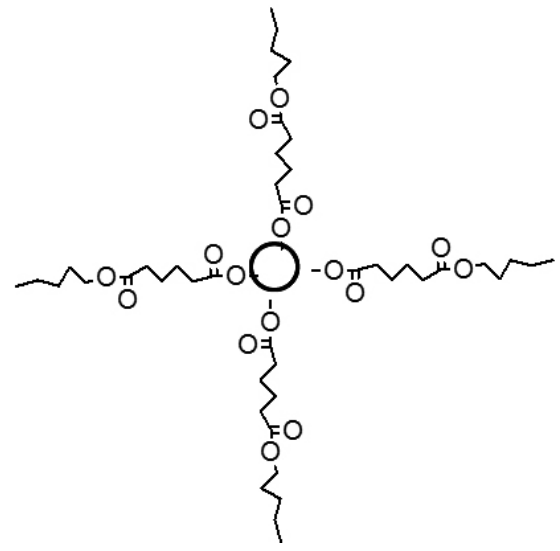

\subsubsection{Covalent grafting of phosphonic acid}

In a study phenyl phosphonic acid (PPA) has been used to open and interpolate halloysite nanotubes ${ }^{14,86}$. PPA-treated HNTs showed improved dispersal and high mechanical performance in the epoxy systems in comparison to unmodified HNTs. The HNTs inner lumen can be altered by using octadecylphosphonic acid (ODP) modifier ${ }^{56}$. Octadecylphosphonic acid fused to the $\mathrm{Al}_{2} \mathrm{O}_{3}$ in the tubule lumen, not on the surface of siloxanes, So octadecylphosphonic acid-modified halloysite can be further altered by AEAPS coupling on the external surface. In smart composite systems, these modified halloysites can be used as an effective material ${ }^{87}$. Throughout experiment double deionized water (DDI) was used.

3.2.8 Halloysite nanotube modification with ODP and AEAPS

In another study, it is reported that the internal lumen of halloysite nanotubes can be altered with ODP ${ }^{140}$. The halloysite nanotubes were mixed with ODP in ethanol-water mixture. Then, the mixture was evacuated many times. The appearance of bubbles showed the removal of air from the lumen of nanotubes with the ODP mixture. One week stirred halloysite at room temperature were washed, centrifuged and dried. Octadecylphosphonic acid fused to the $\mathrm{Al}_{2} \mathrm{O}$ in the tubule lumen, not on the surface of siloxanes, So octadecylphosphonic acid-modified halloysite further can be altered by AEAPS silane coupling on the external surface. This type of modification using a hydrophilic silicate shell and a hydrophobic aliphatic molecules' core can be used for $\mathrm{H}_{2} \mathrm{O}$ purifications, drug immobilizations, and precise discharge. Figure 10 and 11 are symbolical representations of the modifications. 


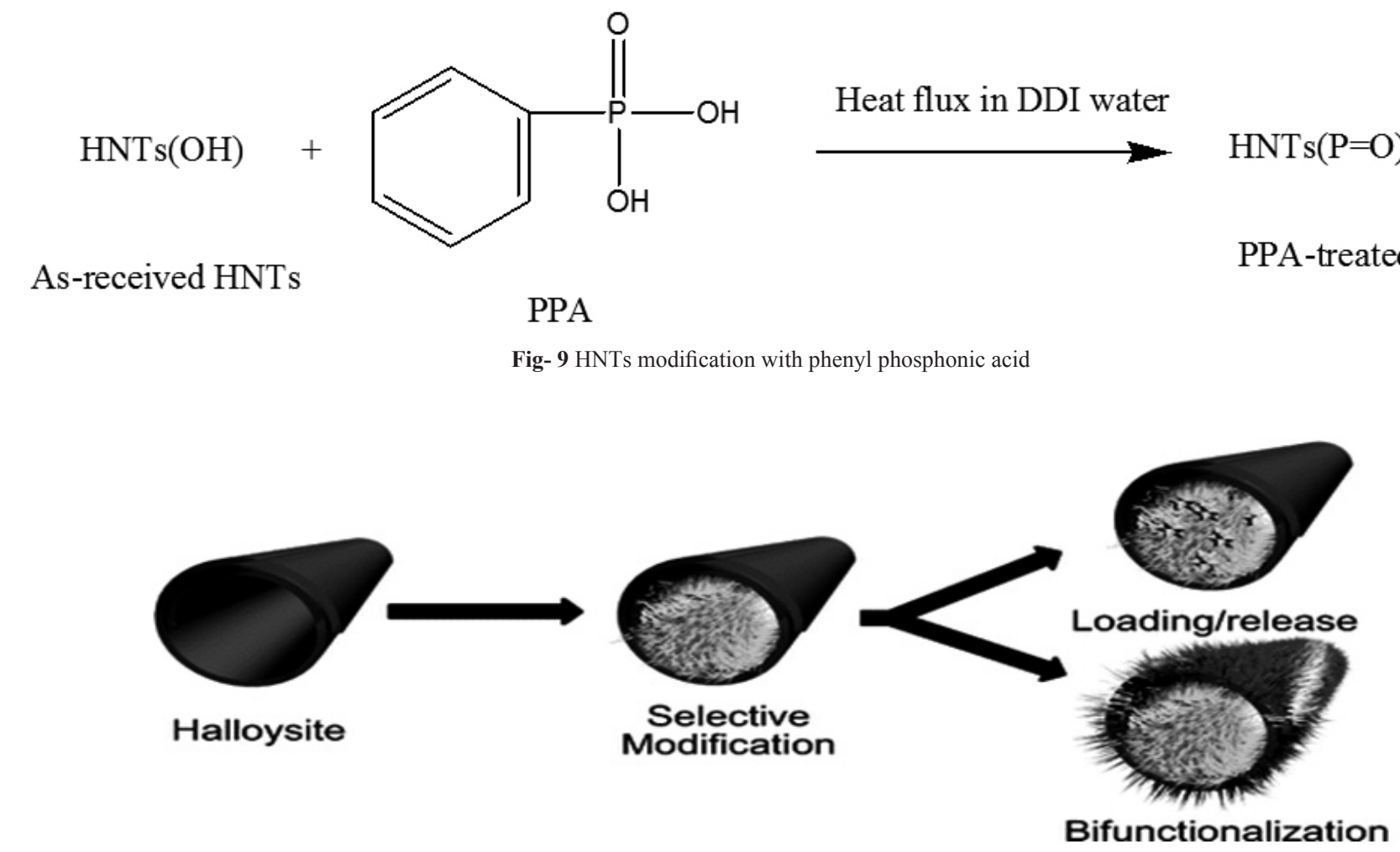

Fig- 10 Selective modification of HNTs lumen with ODP ${ }^{140}$

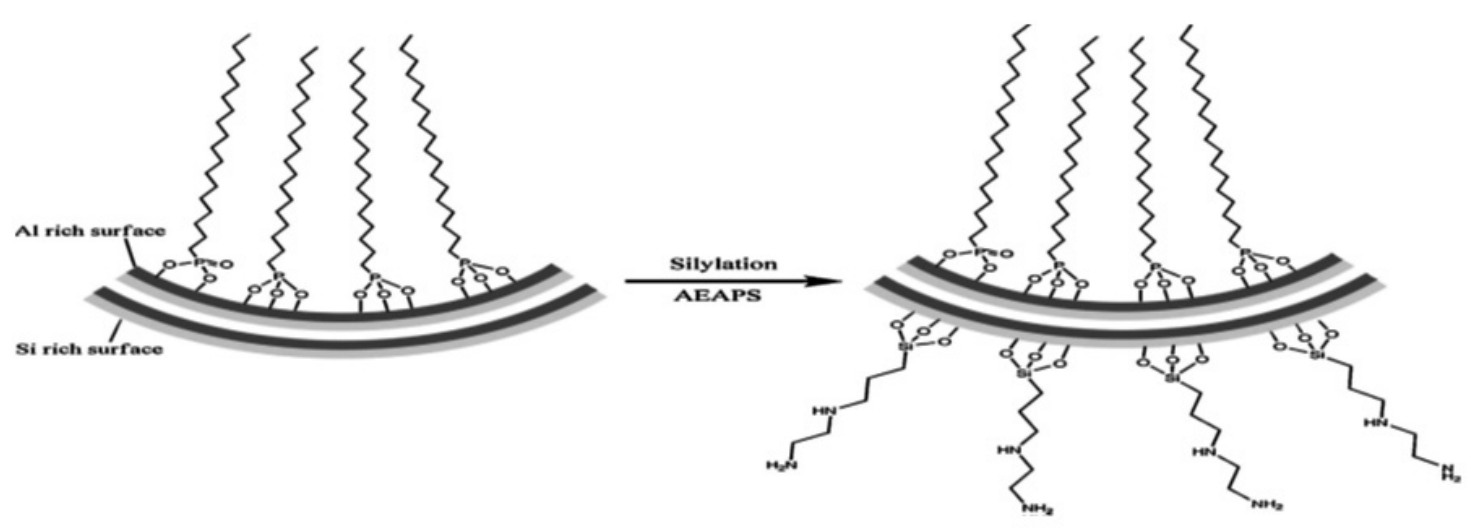

Fig- 11 HNTs modification with ODP and AEAPS ${ }^{140}$

3.2.9 Halloysite modification by Hexa-decyl-tri-methyl-ammonium bromide

Khunova et al. reported the HNTs modification by Hexa-decyl-tri-methylammonium bromide (HEDA). A $5 \%$ solution of HEDA was used for the treatment of purified halloysite nanotubes at $80^{\circ} \mathrm{C}$ for $24 \mathrm{~h}$. After filtration, the HNTs were dried in a vacuum oven at $60^{\circ} \mathrm{C}$ for $24 \mathrm{~h}$. The dried powder was ground and sieved again ${ }^{88}$.

3.2.10 Halloysite modification by 3-aminopropyltrimethoxysilane

Khunova et al. reported the modification of halloysite by 3-aminopropyltrimethoxysilane was performed by adding silane A1100 in water/ethanol solution adjusted by acetic acid to $\mathrm{pH} 5.0^{88}$.

3.2.11 Halloysite intercalation by urea

mechanochemical (dry grinding) method was utilitzed to intercalate the urea within halloysite nanotube. The urea and clay were mixed in 1:2 mixing ratio up to $10 \mathrm{~g}$ mixture was developed by employing a Fritsch Pulverisette $5 / 2$ type laboratory planetary mill. An $80 \mathrm{~cm}^{3}$ capacity stainless steel bowl containing 29 (110.3 g total) stainless steel balls (10 mm diameter each) were used for milling at rotation speed $374 \mathrm{rpm}$ for $30 \mathrm{~min}^{88}$.

3.2.12 L- lactic acid for surface modification of HNTs

$\mathrm{Xu}$ et al. reported the modification of HNTs using L- lactic acid. In 50 $\mathrm{ml}$ of tetrahydrofuran (THF), $5 \mathrm{~g}$ of halloysite nanotubes were dispersed after that at a constant stirring specific amount of L-lactic acid was added in drops. The prepared suspension was heated at $60{ }^{\circ} \mathrm{C}$ for 30 minutes. Then THF was removed by evaporation and $100 \mathrm{ml}$ of dry toluene was added. Then the whole reaction mixture was kept at $110{ }^{\circ} \mathrm{C}$ for 15 hours, by filtration the mixture was collected and rinsed 5 times with THF and moisture free ethyl alcohol correspondingly. The removal of the remaining solvent was done under vacuum at $50{ }^{\circ} \mathrm{C}$ for 24 hours. L-lactic acid modified halloysite (L-halloysite) were achieved. After that a mixture of lactic acid modified halloysite (L-halloysite), L-lactic acid and a definite quantity of p-toluene sulfonic acid were poured into a three-necked flask. At $150{ }^{\circ} \mathrm{C}$ temperature the reaction system was heated and for 30 hours, the water formed was removed by azeotropic dehydration using xylene. Then the product mixture was centrifuged and rinsed 5 times first with chloroform and then with dry ethyl alcohol. After drying in a vacuum oven for 
24 hours at $50^{\circ} \mathrm{C}$, surface-modified halloysite with PLLA (p-halloysite) was achieved ${ }^{89}$.

3.2.13 Halloysite nanotubes modification with sodium dodecyl sulfate

Lun et al. used a chemical method for the modification of halloysite nanotubes. First of all, the impurities of raw halloysite nanotubes were removed by hand picking method. After that, distilled water washed halloysite nanotubes were dried at $60{ }^{\circ} \mathrm{C}$ for 12 hours. Now in half a liter of distilled water, five gram of cleaned halloysite nanotubes and 0.61 grams of anionic surfactant sodium dodecyl sulfate (SDS) were added and the whole mixture was stirred for five hours to make SDS/HNTs suspension. After that, the suspension was centrifuged to separate the product phase. Then the product was dried at 80 ${ }^{\circ} \mathrm{C}$. The prepared sample was named SDS/HNTs. The reaction parameters like dispersion time, the concentration of SDS, solid-liquid ratio and stirring speed were changed to see their effects on the stability of SDS/HNTs suspensions. The conditions would not be strongly acidic or basic for that the excessive acid or base would abolish the structure of halloysite nanotubes ${ }^{90}$. The particle size distribution was measured by laser particle size analyzer (LS-POP6) ${ }^{91}$ Cavallaro et al. prepared surfactant modified halloysite nanotubes. $0.02 \mathrm{~g} \mathrm{~cm}^{-3}$ of halloysite was added in the aqueous solution of surfactant $\left(0.1 \mathrm{~mol} \mathrm{~kg}^{-1}\right)$. The formed mixtures were magnetically stirred for 1 day. Subsequently, the prepared dispersions were kept in a vacuum oven with a pressure of 100 mbar overnight at $50{ }^{\circ} \mathrm{C}$. Centrifugation were utilized to detach aggregates with subsequently rinsing many times by the use of water until the surface tension of the supernatant came close to the value for pure water (ca. $72 \mathrm{~m} \mathrm{~N} \mathrm{~m}^{-1}$ ). All the solids were parched at $80{ }^{\circ} \mathrm{C}$ and confirmed by using thermo gravimetric analysis (TGA) to investigate the surfactant loading within the halloysite nanotubes lumen ${ }^{92}$.

Cavallaro et al. developed a technique to gain inorganic reverse-micelles based upon halloysite and alkytrimethylammonium bromide. This specific modification of halloysite' exposed surface using cationic surfactant resulted in formation of hydrophilic cavity and hydrophobic shell functionalized tubular nanostructures. In this study, the influence of the alkyl chain length on halloysite modification was undertaken. The filling of halloysite lumen with hydrophilic compounds was best assisted by solubilizing copper sulfate in water-in-oil emulsion. In this research, Cavallaro et al. prepared environmental compatible reverse micelles with tunable hydrophobic and hydrophilic interface ${ }^{93}$.

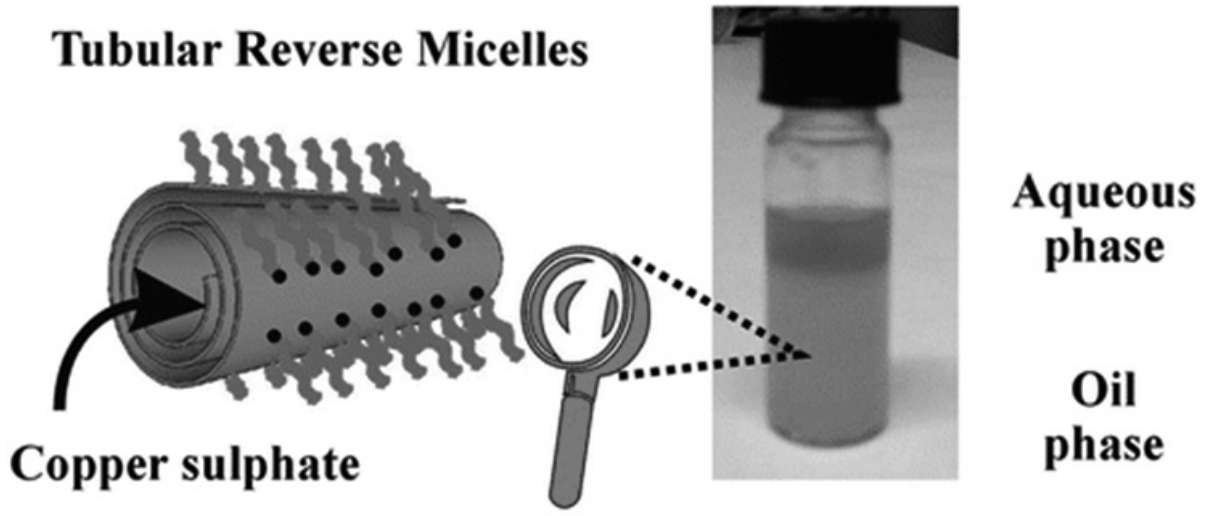

Fig- 12 Halloysite with hydrophobic shell and hydrophilic cavity ${ }^{93}$

In this study, researchers have prepared hybrid HNTs in which the inner cavity of halloysite was selectively modified. Physicochemical study reveals that the interactions between halloysite and sodium alkanoate ruled out the clay exfoliation and increase of the total negative charge, which allowing us to obtain rather stable aqueous clay dispersions. These dispersions were revealed to be nonfoaming and are very efficient in encapsulating oils. Here they prepared biocompatible and low cost inorganic micelles that can be exploited for applications in industry ${ }^{94}$.

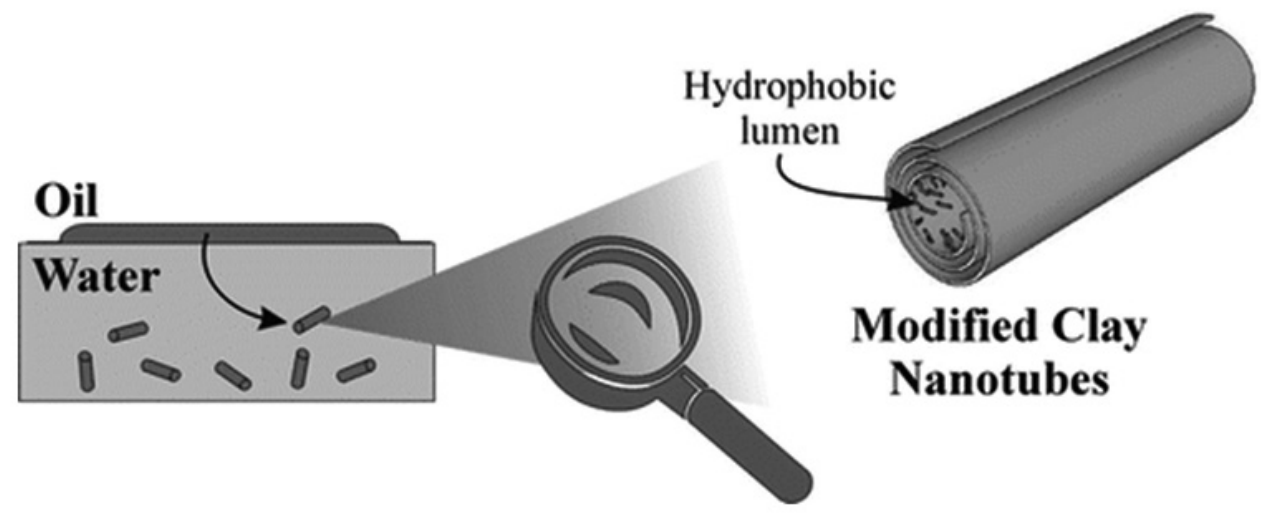

Fig- 13 Preparation of hybrid halloysite nanotube ${ }^{94}$

HNTs are modified by exploiting different charges between inner positive and outer negative surfaces respectively; a selective adsorption is pursued by employing cationic and anionic surfactants. The hybrid materials were dispersed in aqueous phase to observe the colloidal stability, which is important for applications. It was found that the adsorption of anionic surfactant into the lumen of halloysite enhances the net negative charge of the HNTs and electrostatic repulsions which as a result increases the dispersion stability. This can be used for the preparation of hybrid materials such as inorganic micelles which can be used in water for solubilization and delivery of hydrophobic compounds ${ }^{95}$.
3.2.14 Halloysite nanotubes and acid treatment

Zhang et al. reported the effects of acid treatment on halloysite nanotubes. In this work, the influence of sulfuric acid $\left(\mathrm{H}_{2} \mathrm{SO}_{4}\right)$ treatment on physicochemical and pore features of HNTs were studied. X-ray diffraction (XRD) study showed that sulfuric acid damaged the crystalline morphology of HNTs and it changed into amorphous silica. The acid reacted from inner and outer both of the sides by dissolving the octahedral layers $\left[\mathrm{AlO}_{6}\right]$ and rupturing tetrahedral layers $\left[\mathrm{SiO}_{4}\right]$ respectively. Brunauer, Emmett and Teller (BET) surface area and pore capacity of halloysite nanotubes at first improved with treatment times from 1 to 13 hours, and after that it went to fall owing 
to disaggregation of silica layers. Halloysite nanotubes treated with acid are effective low cost adsorbents due to their fixed micropores and controllable mesopore size distributions. For methylene blue, halloysite treated with acid showed the highest adsorption capacity higher than $60 \mathrm{mg} \mathrm{g}^{-1}$ and is controllable by controlling $\mathrm{pH}$. Additionally, the acid treated HNTs are potential supporters for drugs, enzymes, sensors, and so on ${ }^{90}$.

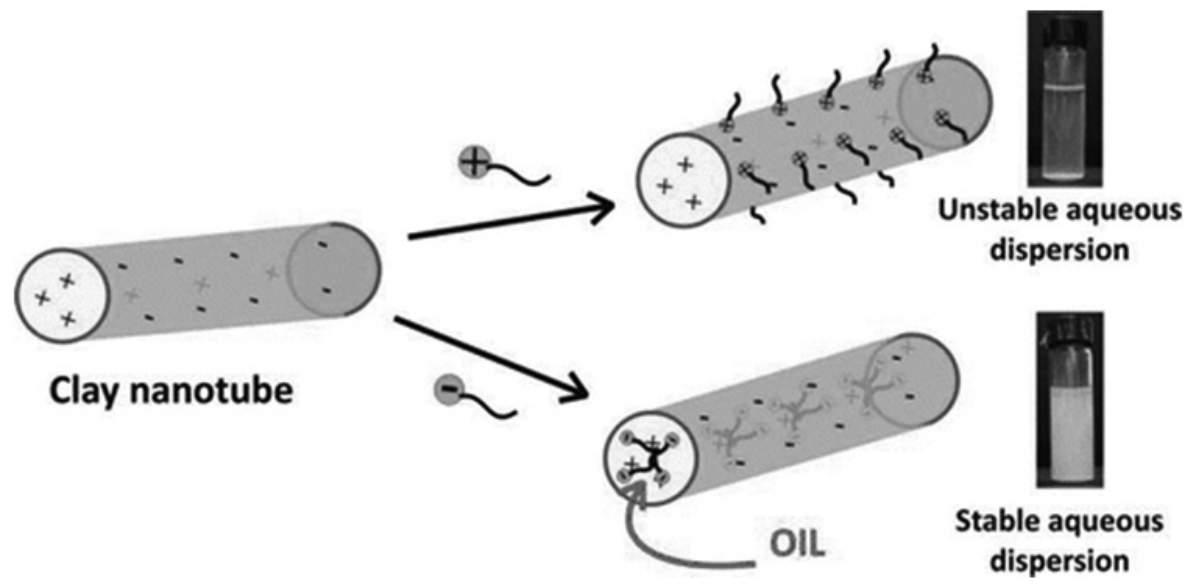

Fig- 14 HNTs modification with cationic and anionic surfactants ${ }^{95}$

3.2.15 Treatment of halloysite nanotubes with potassium acetate

Deng and Ye studied the influence of potassium acetate treatment on halloysite nanotubes. Potassium acetate (PA), $\mathrm{CH}_{3} \mathrm{COOK}$, was used to treat HNTs to improve particle dispersion in epoxy resin and their compatibility. 11 grams of $\mathrm{PA}$ and $10 \mathrm{ml}$ of hydrochloric acid $(\mathrm{HCl})(12 \mathrm{~mol} / \mathrm{L})$ were added into $1000 \mathrm{ml}$ of deionized water in a glass beaker to prepare potassium acetate solution, after that 100 grams of halloysite nanotubes were slowly added into the solution, the whole solution was stirred for $5 \mathrm{~h}$ at $60{ }^{\circ} \mathrm{C}$. Then the mixture was kept as two layers (liquid and solid) were formed. The treated halloysite nanotubes were finally separated and were kept at room temperature for the complete removal of moisture. The dried mass was ground to fine powder and were screened with a fine metal sieve ${ }^{96}$.

\subsection{Non-covalent functionalization}

\subsubsection{Depends on electron transfer interactions}

It is studied that due to less hydroxyl groups on surface of HNTs we need non covalent functionalization. The occurrence of several metallic atoms like $\mathrm{Al}, \mathrm{Fe}$ and transition metals with vacant orbitals on HNTs can enhance the interfacial characteristics of halloysite nanotubes and organic molecules or polymers through electron transfer interactions ${ }^{59,97}$. 2,2-(1,2- ethene diyldi4,1-phenylene) bisbenzoxazole (EPB) and 2,5-bis(2-benzoxazolyl) thiophene (BBT) ${ }^{98}$ molecules are able to donate electrons. The nanocomposites with BBT exhibited improved mechanical properties. In situ interfacial properties can be improved by this technique.

\subsubsection{Based on hydrogen bonding interactions}

It is reported that many of the organic compounds like melamine cyanurate (MCA), melamine (MEL) and diphenyl guanidine (DPG) can interrelate with halloysite through $\mathrm{H}$-bond interactions ${ }^{99,}{ }^{100}$. The organic species and HNTs were mixed concurrently to the resins during polymer processing. This method is actually a green process so by using we can improve the flexural modulus of the polypropylene (PP) composites and to reinforce polar polyamide-6 (PA6).

\subsubsection{Based on the electrostatic attraction}

Kelly et al. and Lvov et al. reported that halloysite can interact with cationic polymers like PEI and chitosan through electrostatic forces. These interactions are used for the surface-treatment of halloysite nanotubes. Halloysite nanotubes coating with cationic polymers and their binding on the negatively charged surface of the tubes can delay drug release ${ }^{101,102,144,145}$.

4. MULTIFARIOUS METHODS OF MODIFICATION OF

\section{HALLOYSITE}

4.1 DNA wrapped halloysite nanotubes

Halloysite nanotubes have aluminol groups inside the tubes and siloxanes on the surface of tubes. A few aluminol groups and silanol groups are present on the boundaries. These characteristics make halloysite nanotubes a typical filler from other fillers such as clays ${ }^{103,130}$.

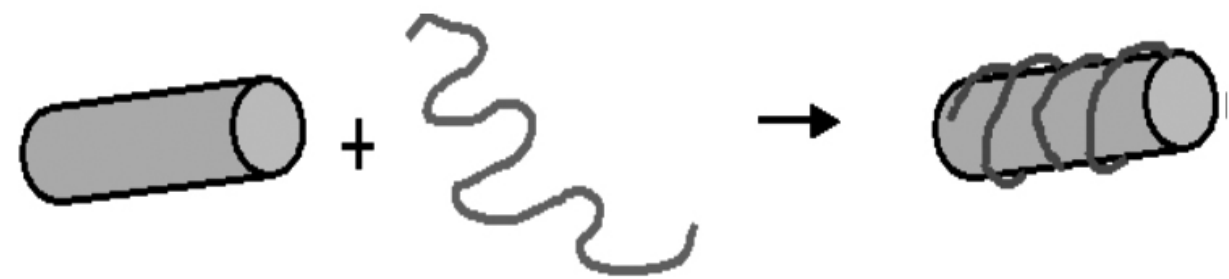

HNT DNA

HNT--DNA

Fig- 15 Formation of DNA wrapped halloysite nanotube ${ }^{103}$

In another study, it is reported that the biocompatibility of halloysite nanotubes can be improved through non- covalent functionalization with biological molecules. A supramolecular complex of halloysite, deoxyribonucleic acid (DNA) and amylose is made by mechanical force. The prepared molecular complex shows higher dispersal in dimethyl sulfoxide / water solutions ${ }^{104}$

In a separate study biopolymer with dissimilar charges like pectin (anionic), hydroxypropyl cellulose (neutral) and chitosan (cationic) were adsorbed onto the halloysite. Turbidity was used to assess the stability of HNTs in water. It was observed that the interactions of treated HNTs with polymeric systems give the production of the colloidal system with tailor made stabilities and surface characteristics. This gives various perspective on novel uses of such colloidal dispersions, e.g., as carriers for releasing active material in response to external stimulus ${ }^{105}$. 


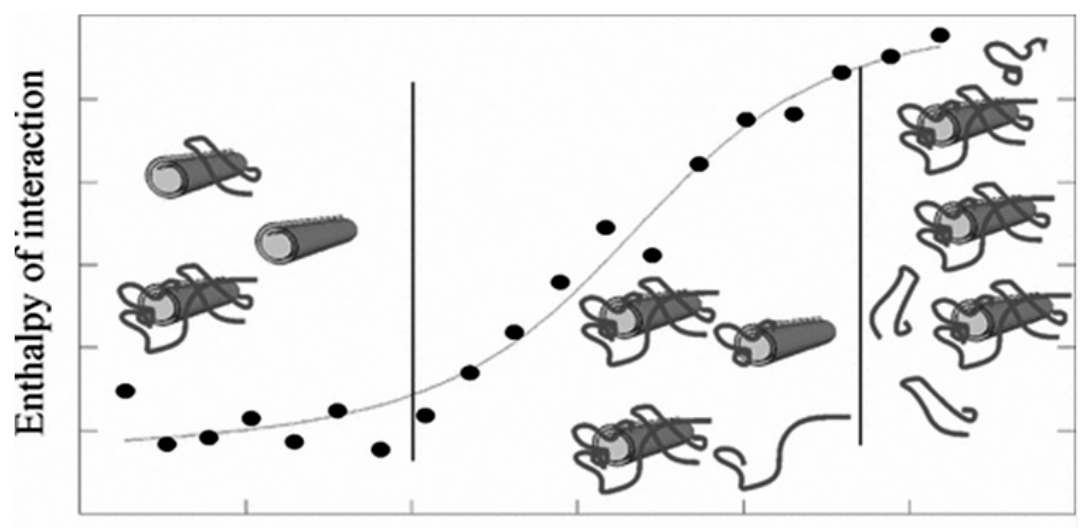

Polymer/Nanotube Ratio

Fig- 16 Biopolymers adsorbed on halloysite nanotube ${ }^{105}$

In another study, bionanocomposites were synthesized and the influence of polymer charge, filler geometry and composition were indicated and dependence of final performance of composites on these parameters was studied. Various biopolymers like chitosan, alginate and methylcellulose were combined with two types of nanoclays, one was kaolinite and other was HNTs to synthesize the nanocomposites from the water. Mechanical properties and thermal stability and were studied. SEM was also used to study the morphology of the nanocomposites ${ }^{106}$.

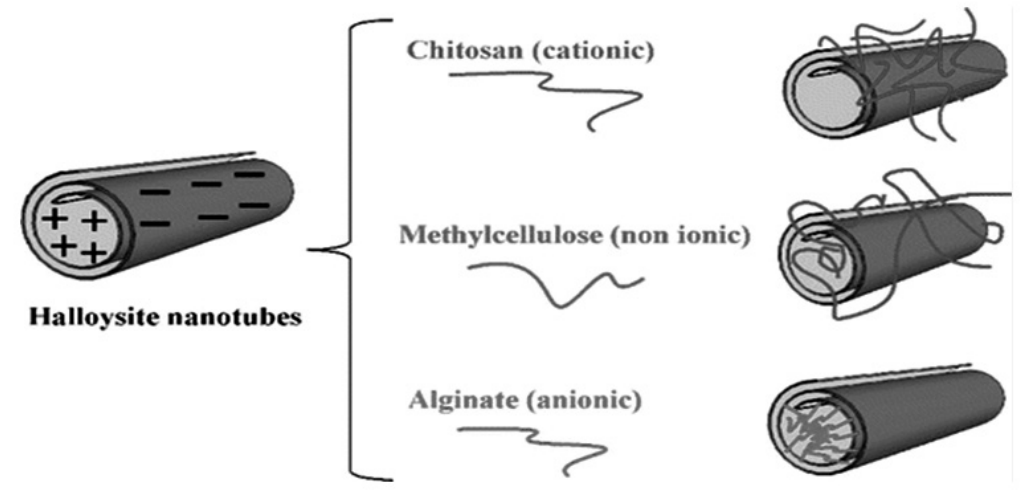

Fig- 17 Biopolymers adsorbed on halloysite nanotube ${ }^{106}$

\subsection{Intercalation of HNTs}

Joussein et al. reported the intercalation of HNTs with salts and organic compounds ${ }^{11}$. Khunova et al. studied the urea-intercalated halloysite nanotubes reinforce polypropylene (PP) superior to unchanged halloysite nanotubes ${ }^{88}$

4.3 Enlargement of the lumen in HNTs

Many researchers reported that the opening of inner pores by using chemical treatment is important $107-109,141-143$. Using sulfuric acid of $0.5-2 \mathrm{M}$, lumen diameter was improved from 15 to $25 \mathrm{~nm}$ improving the lumen capability 107. The halloysite loading effectiveness increased 4-fold for benzotriazole ${ }^{108}$. Acidic and basic treatments provided a suitable means for improving the pore capacity and surface area of halloysite nanotubes without considerably changing of their morphology. The porosity can be modified by varying the $\mathrm{pH}$ of water suspension having halloysite nanotubes ${ }^{109}$. The uniqueness of HNTs pores might be valid for drug delivery methods and for the loading of nanomaterials. The internal diameter of halloysite nanotubes is almost 15-100 $\mathrm{nm}$. Joo et al. reported that the pore size can be changed by varying the acidity of $\mathrm{H}_{2} \mathrm{O}$ mixture having halloysite nanotubes. Halloysite nanotubes can act as entrances for each other, hindering the lumen through clumps formation or opening it through dispersal. It is reported that the inside-pores of halloysite nanotubes were opened through basic treatment by negative charge dispersal; and these pores were locked after neutral and acidic treatments.

4.4 Halloysite nanotubes modification with dopamine

Chao et al. studied that HNTs can be used as a probable support for the immobilization of enzymes. For practical applications the improvements in enzyme loadings onto halloysite nanotubes is critical. Literature suggests that dopamine can self-polymerize to stick to the exterior of halloysite nanotubes and make a thin dynamic layer. These hybrid halloysite nanotubes were used for the immobilization of enzymes of laccase, at the same time high loading capacity $(168.8 \mathrm{mg} / \mathrm{g})$ was seen, that is significantly better than on the virgin halloysite nanotubes which is $11.6 \mathrm{mg} / \mathrm{g}$. The immobilized laccase can keep higher than ninety percent primary functionality post thirty days of stowage and unimmobilized laccase just thirty-two percent. Furthermore, the immobilized laccase showed a fast decomposition rate and high decomposition efficacy to remove the phenolic compounds. This showed that this type of hybrid materials may be used as a cheaper and active support for the immobilization of enzymes 110 . 


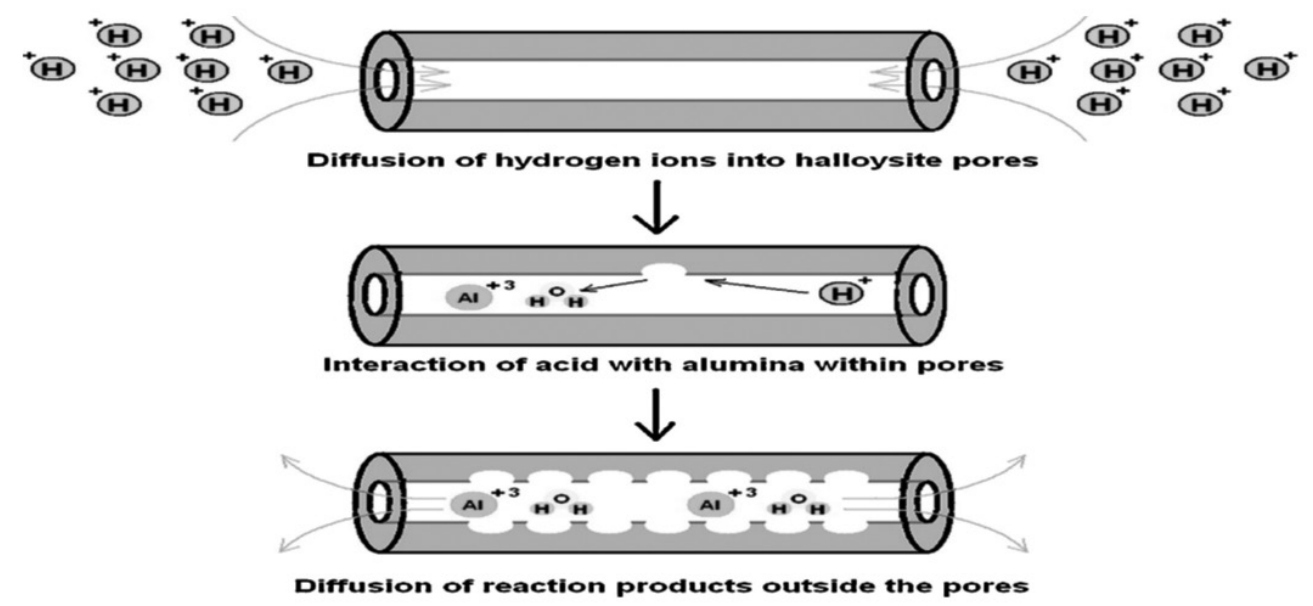

Fig- 18 Improvement of the lumen by acid etching of alumina in internal layers of halloysite ${ }^{107}$
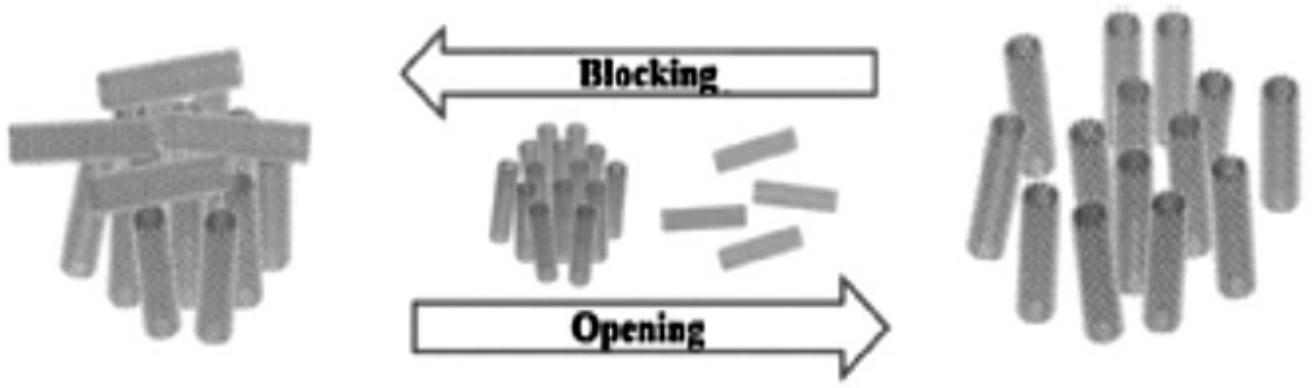

Acid and neutral treatment ( $\mathrm{pH} \mathrm{2,7)}$

Base treatment $(\mathrm{pH} 11)$

Fig- 19 Internal space of halloysite treated with various solutions ${ }^{109}$

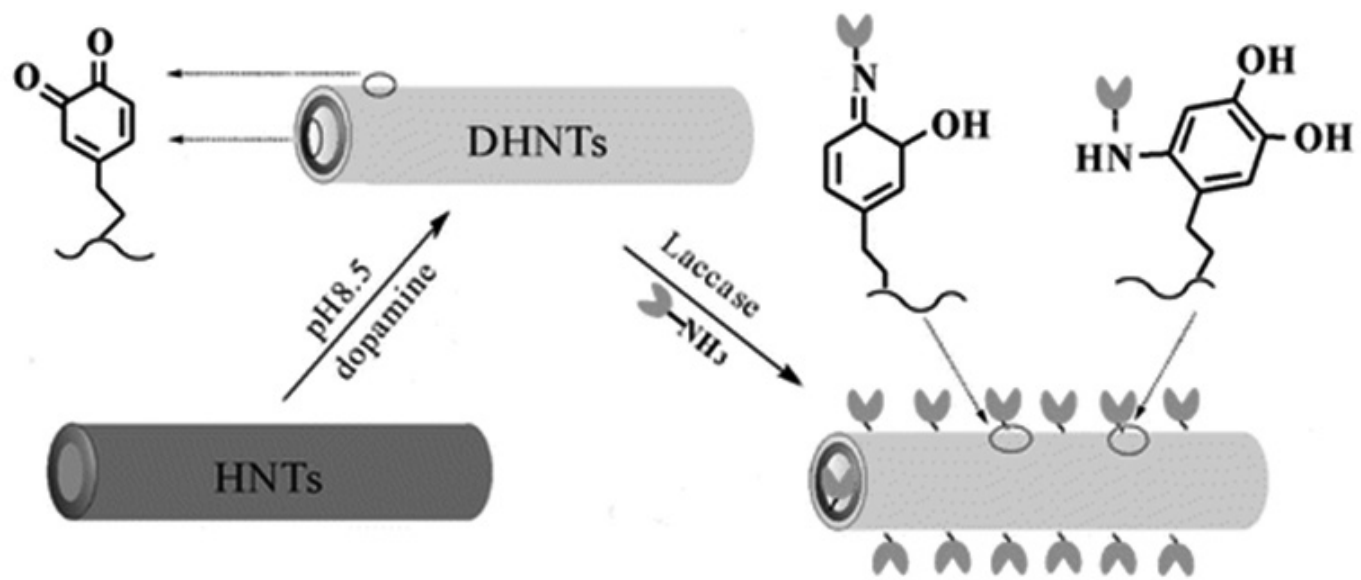

Fig- 20 HNTs modification with dopamine ${ }^{110}$

4.5 Modifications of HNTs with super paramagnetic $\mathrm{Fe}_{3} \mathrm{O}_{4}$ nanoparticles and carbonaceous layers

Ling et al. studied the surface modification of HNTs in situ with grown $\mathrm{Fe}_{3} \mathrm{O}_{4}$ nanoparticles. The structure study revealed that nanoparticles of iron oxide were homogeneously decorated onto the HNTs and forming a layer that gives better properties to $\mathrm{HNTs} / \mathrm{Fe}_{3} \mathrm{O}_{4}$ /carbon composite. Magnetism proves the super paramagnetic performance of $\mathrm{HNTs} / \mathrm{C} / \mathrm{Fe}_{3} \mathrm{O}_{4}$ hybrid at room temperature, that able it easy to separate from the dye solution with the influence of the external magnetic field. Adsorption abilities revealed the adsorption capacities of the fabricated $\mathrm{HNTs} / \mathrm{Fe}_{3} \mathrm{O}_{4} /$ carbon composite are about 1.5 times for methylene blue (MB) as compared to that of HNTs/ $\mathrm{Fe}_{3} \mathrm{O}_{4}$ and halloysite nanotubes according to Langmuir equation, respectively. Therefore, the fabricated HNTs/ $\mathrm{Fe}_{3} \mathrm{O}_{4}$ /carbon hybrid is a fast, separable and super paramagnetic adsorbing capabilities with better adsorption functionality, 
presenting extraordinary prospective regarding water treatment applications ${ }^{111}$ 4.6 Modification of the hydroxyl surface of PA intercalated HNTs between 25 and $300^{\circ} \mathrm{C}$

Frost et al. studied the variations in the hydroxyl surfaces of PAintercalated HNTs over ambient to pre-dehydroxylation temperature range using XRD and Raman spectroscopy. XRD reveals that the HNTs was entirely stretched to $13.80 \AA$. PA-intercalated HNTs complex when heat to $50^{\circ} \mathrm{C}$ in inert atmosphere, two stretched phases were detected having $d$-spacings of 8.95 and $11.47 \AA$. The phase with $11.47 \AA d$-spacing was remained stable in both the cooling and heating cycles during thermal treatment. The phase with $8.95 \AA$ $d$-spacing underwent an enlargement at $100^{\circ} \mathrm{C}$ to $9.2 \AA$. In a normal atmosphere, the intercalated kaolinite come back to a $13.80 \AA$ phase. The fully intercalated HNTs exhibited a band at $3602 \mathrm{~cm}^{-1}$ referred to the inside surface hydroxyl hydrogen bonded to the acetate ion together with bands at 3620 and $3695 \mathrm{~cm}^{-1}$ assigned to the inner hydroxyl and the inner surface hydroxyls, which do not react with the acetate. Slight heating of the PA-intercalated HNTs complex to $50^{\circ} \mathrm{C}$ caused a rearrangement of the surface structure with Raman bands being observed at 3606 and $3597 \mathrm{~cm}^{-1}$. Additional heating treatment at $100^{\circ} \mathrm{C}$ caused these bands to move to 3615 and $3601 \mathrm{~cm}^{-1}$. At the pre-dehydroxylation temperature for potassium acetate intercalated halloysite $\left(300^{\circ} \mathrm{C}\right)$ two bands were observed at 3602 and $3612 \mathrm{~cm}^{-1}$. Not any hydroxyls are spectroscopically obvious above this temperature. The Raman spectra of the hydroxyl surfaces are changed with two bands detected at 3596 and $3604 \mathrm{~cm}^{-1}$ on cooling to room temperature, ${ }^{112}$ HNTs

4.7 Preparation of 3-mercapto-propyl trimethoxysilane modified

\subsubsection{Classical procedure}

Massaro et al. reported the modification of halloysite by organosilane. One $\mathrm{ml}$ of 3-mercapto-propyl trimethoxysilane was mixed with $20 \mathrm{ml}$ of moisture free toluene. Then 3 grams of halloysite powder was poured and the whole mixture was ultra-sonicated for twenty minutes. After that, the suspension was refluxed at $120^{\circ} \mathrm{C}$ temperature for 20 hours at continuous stirring. The obtained mass was filtered and rinsed with methanol to remove the additional organosilane. Then it was dried at $80^{\circ} \mathrm{C}$ in vacuum for one night ${ }^{113}$

\subsubsection{Microwave irradiation (MW)}

According to Massaro et al. first of all one gram of halloysite nanotubes was suspended in microwave test tube. The $5 \mathrm{ml}$ of moisture free toluene and $2 \mathrm{ml}$ of 3-mercaptopropyl trimethoxysilane were poured in drop wise. After that, the whole mixture was stirred for one hour using ultrasonicator in the microwave at $80^{\circ} \mathrm{C}$. The solid mass was filtered washed with methanol and then it was dried at $80^{\circ} \mathrm{C}$ in vacuum ${ }^{113}$.

\subsubsection{Solvent-free MW irradiation}

In another study, Massaro et al. modified the halloysite nanotubes in solvent free atmosphere. First of all one gram of halloysite nanotubes was suspended in microwave test tube. $2 \mathrm{ml}$ of 3-mercaptopropyl trimethoxysilane were poured in drop wise. After that, the whole mixture was stirred for one hour using ultrasonicator in microwave at $80^{\circ} \mathrm{C}$. The solid mass was filtered washed with methanol and then it was dried at $80^{\circ} \mathrm{C}$ in vacuum ${ }^{113}$.

\subsection{Preparation of ionic liquid modified HNT}

4.8.1 Classical procedure

Massaro et al. reported that the modified halloysite nanotubes $(0.500$ g) were suspended in dichloromethane (DCM) $(4 \mathrm{ml})$ then suitable ionic liquid $(2 \mathrm{mmol})$ was poured into the above suspension. Now catalyst azobisisobutyronitrile (AIBN) was added and the whole mixture was refluxed for 42 hours. Now the solid mass was filtered and washed with DCM and dried at $80^{\circ} \mathrm{C}$ under vacuum.

\subsubsection{Microwave irradiation}

Massaro et al. also reported that the modified halloysite nanotubes $(0.100$ g) were added in $2 \mathrm{ml}$ of dichloromethane (DCM) then $0.4 \mathrm{ml}$ of suitable ionic liquid was poured into the above suspension. The mixture was kept in the microwave oven at $40{ }^{\circ} \mathrm{C}$ for one hour. Now the solid mass was filtered and washed with DCM and dried at $80^{\circ} \mathrm{C}$ under vacuum ${ }^{113}$

\subsubsection{Solvent-free $M W$ irradiation}

Massaro et al. also reported that the modified halloysite nanotubes $(0.100$ g) was added into a microwave tube, then $0.4 \mathrm{ml}$ of suitable ionic liquid was poured into it. The mixture was kept in the microwave oven at $50{ }^{\circ} \mathrm{C}$ for one hour. Now the solid mass was filtered and washed with DCM and dried at $80^{\circ} \mathrm{C}$ under vacuum ${ }^{113}$.

4.9 Chemical modification of HNTs

Szczepanik et al. reported that the bleached halloysite $(\mathrm{BH})$ models were acquired by the pristine HNTs which were proceeded via washing, drying and grinding; next, the magnetic fraction of raw halloysite nanotubes was parted by $2-\mathrm{T}$ magnetic separator. Washing and drying of obtained non-magnetic fraction of HNTs mineral were employed by using deionized water with subsequent sodium hydrosulfite reductive bleaching. The luster upgrading and highest HNTs recovering was achieved via removal of coloring titanoferrous impurities from raw halloysite ${ }^{114}$.

4.10 Acid treatment of halloysite

Drying of raw halloysite, grounding them to fine powder and screening by use of sieve of $0.2 \mathrm{~mm}$ diameter, then cleaning with distilled water were followed for acid treatment of halloysite. $250 \mathrm{~g}$ of washed and dried raw halloysite was mixed 25 mass $\% \mathrm{H}_{2} \mathrm{SO}_{4}$ solutions upto $800 \mathrm{~mL}$. The suspension was stirred for 4 hours at $80^{\circ} \mathrm{C}$. The method was repeated in various conditions: the temperature of $110^{\circ} \mathrm{C}$ and 50 mass $\% \mathrm{H}_{2} \mathrm{SO}_{4}$ solution. The modified HNTs were filtered, cleaned with distilled water, after that parched for $24 \mathrm{~h}$ at $100^{\circ} \mathrm{C}$ and grounded to powder. The obtained materials were labeled as acid-treated HNTs - ATH25 and ATH50 ${ }^{114}$

4.11 HNTs modification with 4-chloroaniline (4CA)

Szczepanik et al. studied that soaked bleached HNTs (B-HNTs) for 25 hours in ultra-pure water from the Milli Pore system for $24 \mathrm{~h}$, this aqueous solution was mixed with 4-chloroaniline concentration of $200 \mathrm{mg} / \mathrm{dm}^{3}$. After $24 \mathrm{~h}$, the halloysite samples containing adsorbed 4-chloroaniline were dried for 24 hours at $80^{\circ} \mathrm{C}$ and made their powder ${ }^{114}$.

4.12 Synthesis of hydroxylated HNTs (h-HNTs)

Zeng et al. prepared hydroxylated HNTs. First of all organic impurities were removed from HNTs by using $\mathrm{H}_{2} \mathrm{O}_{2}$ Normally, $30 \mathrm{~g}$ of the pristine HNTs were poured in $200 \mathrm{ml} 30 \% \mathrm{H}_{2} \mathrm{O}_{2}$ aqueous solution and stirred magnetically for one hour. The HNTs were dispersed in ultra-sonicated bath for ten minutes. The obtained purified halloysite nanotubes ( $\mathrm{p}$-halloysite) were first dried for 12 hours at $110^{\circ} \mathrm{C}$ in oven and then dried in a vacuum oven at for 12 hours at $60^{\circ} \mathrm{C}$. To improve the dispersal of halloysite nanotubes within the epoxy matrix, the previously treated halloysite was modified with sodium hydroxide. Usually, $2 \mathrm{~g}$ of treated HNTs were stirred in $100 \mathrm{ml}$ distilled water. After that, $58 \mathrm{mg}$ sodium hydroxide was mixed and the system was stirred magnetically at room temperature for 24 hours. The resulting hydroxylated halloysite nanotubes (h-halloysite) solid mass was then parted by centrifuging and washing many times with distilled water until the neutral solution obtained. The synthesized h-halloysite were parched in an oven for twelve hours at $110^{\circ} \mathrm{C}$ and again parched in a vacuum oven at $60^{\circ} \mathrm{C}$ for twelve hours ${ }^{115}$.

\subsection{Functionalization of HNTs by APTES}

In another study, Hemmatpour et al. reported the modification of HNTs with APTES. APTES silane coupling on the HNTs' surface was employed by reacting exposed hydroxyl motilities. $2.4 \mathrm{gm}$ of halloysite nanotubes were dispersed in $100 \mathrm{ml}$ toluene and stirred for two hours. After that, $8 \mathrm{ml}$ of APTES was mixed and the mixture was dispersed sonically for 30 minutes. Refluxing of mixture was continued for $24 \mathrm{~h}$ at $110^{\circ} \mathrm{C}$, then cooling and purification was done in $60 \mathrm{ml}$ toluene two times to seperate the unreacted APTES. $1.92 \mathrm{gm}$ of HNTs- $\mathrm{NH}_{2}$ was yielding after drying at $75^{\circ} \mathrm{C}^{116}$

4.14 Modification of HNTs-NH by alpha-bromoisobutyryl bromide (BiBB)

Hemmatpour et al. reported the modification of HNTs with BiBB. 0.5g of HNTs- $\mathrm{NH}_{2}$ was taken and poured in twenty (20) $\mathrm{ml}$ chloroform and stirred for thirty minutes. After that, $1.5 \mathrm{~g}$ 4-dimethylaminopyridine (DMAP) and $10 \mathrm{ml}$ triethylamine were charged to the reaction chamber under inert atmosphere. After this $8 \mathrm{ml}$ of BiBB were dissolved in $15 \mathrm{ml}$ of chloroform. The solution was mixed in the reaction chamber drop wise under stirring for 3 hours at $0^{\circ} \mathrm{C}$. After another stirring treatment for 24 hours at room temperature, the mass was removed from the reaction chamber through centrifuge. The attained mass was cleaned with chloroform many times, and also with deionized water and ethanol mixture for three times. 0.36 $\mathrm{g}$ HNTs-Br was yielded after filtering solid mass through a $0.2 \mathrm{~mm}$ PTFE filter and dried the filtrate at $70^{\circ} \mathrm{C}{ }^{116}$.

4.15 Preparation of N-2-Pyridylsuccinamic acid-modified halloysite (HNTs-PSA)

He et al. reported that halloysite was first of all purified by using $10 \%$ $(\mathrm{v} / \mathrm{v}) \mathrm{HCl}$ solution to remove the impurities and the metal ions which were adsorbed on halloysite nanotubes. $5 \mathrm{~g}$ of purified HNTs were mixed with $60 \mathrm{ml}$ of moisture free toluene having $5 \mathrm{ml}$ of 3-aminopropyltrimethoxysilane, then the whole mixture was refluxed for 12 hours. The obtained mass was filtered and cleaned by using ethyl alcohol, toluene and diethyl ether at $60{ }^{\circ} \mathrm{C}$ for 6 hours. The modified HNTs-bound amino propyl phase (HNTs-APTES) were obtained. Now the HNTs-PSA was synthesized using this route (Yanqing et al., 2007), $4 \mathrm{~g}$ of HNTs-APTES, $1 \mathrm{~g}$ of N, N-Dicyclohexylcarbodiimide (DCC), $1 \mathrm{~g}$ of PSA and $50 \mathrm{ml}$ of dimethylfomamide (DMF) were taken in a flask in order and stirred at normal temperature for 24 hours. The resultant mass was filtered, rinsed with DMF and ethyl alcohol and dried under vacuum at $60^{\circ} \mathrm{C}$ for 6 hours ${ }^{117}$. 

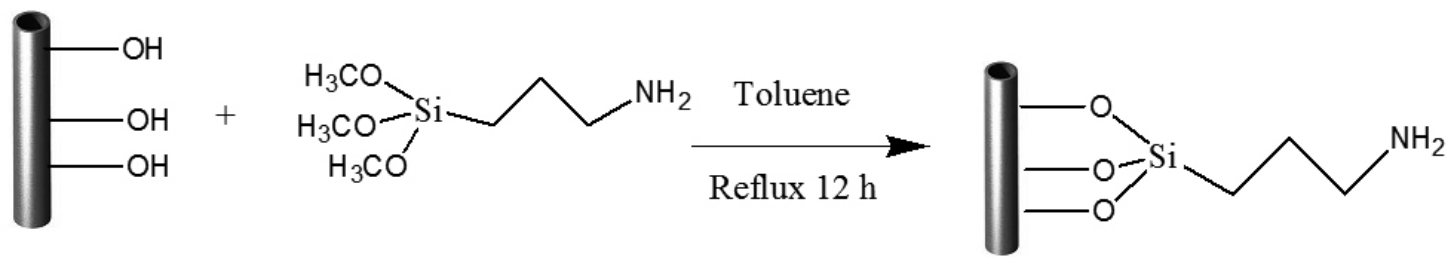

HNTs

Fig- 21 Modification of HNTs with APTES ${ }^{110}$

HNTs-APTES

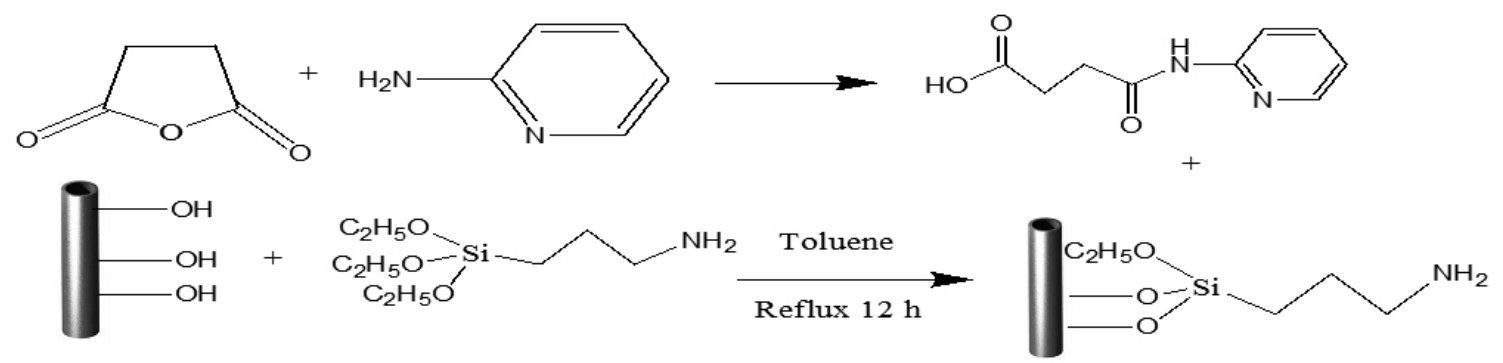

HNTs

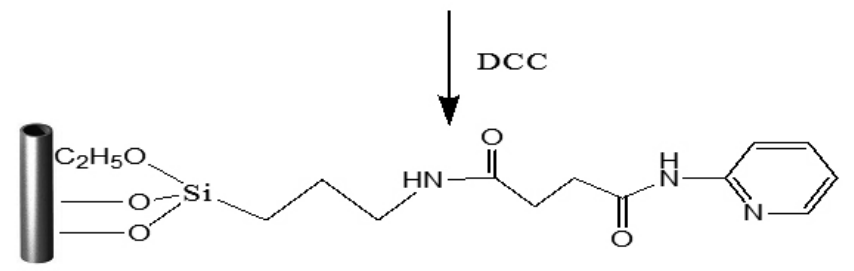

HNTs-PSA

Fig- 22 Synthesis route of HNTs-PSA ${ }^{117}$

\subsection{APTES and DGEBA modified HNTs}

In a separate study, Vahedi and Pasbakhsh reported the modification of halloysite with APTES and DGEBA. HNTs and the modifying reagents (DGEBA or APTES) were mixed with toluene and stirred for 30 minutes. The whole reaction has proceeded in three-necked flask equipped with $\mathrm{CaCl}_{2}$ to keep the environment dry. After the addition of cobalt naphthenate catalyst, the mixture was refluxed at $110^{\circ} \mathrm{C}$ for 24 hours and the resulting mixture was filtered, rinsed and dried for 24 hours at $110^{\circ} \mathrm{C}$. Before modification, heat or $\mathrm{NaOH}$ pretreatment of halloysite was performed to alter hydroxyl groups' concentration on halloysite nanotubes surface. The resulting mixture was filtered by centrifugation method and rinsed expansively with deionized water to remove the possible relic of $\mathrm{NaOH}$. The separated mass was then dried for 24 hours at $50^{\circ} \mathrm{C}$ earlier to modification practice ${ }^{118}$.

4.17 Planetary ball-milling treatment of HNTs in the presence of polyethylene glycol (PEG)

He et al. treated the HNTs by planetary ball milling in the presence of polyethylene glycol (PEG). HNTs (15g) along with PEG $(0.30 \mathrm{~g})$ were poured into $150 \mathrm{ml}$ of deionized water or ethanol/deionized water mixture of various mixing ratio. The ball-milling at a speed of $800 \mathrm{rpm}$ for 4 hours with subsequent centrifuge to obtain precipitates. The free polyethylene glycol marocmolecules were eliminated from precipitates by washing them many times with deionized water or ethanol/water mixture of equal volumes and them dried them in freezing dryer to obtain treated HNTs powder. The precipitate were washed with deionized water or water/ethanol mixture $(50 / 50, \mathrm{v} / \mathrm{v})$ for many times to eliminate the free polyethylene glycol macromolecules and then dried in a freezing dryer to get modified HNTs powder. Furthermore, aqueous suspension of HNTs was achieved by cells grinding of HNTs powder and redispersing them in deionized water under ultrasonic dispersion method ${ }^{119}$.

4.18 Organosilane modification of HNTs

In a separate study, Bischoff et al. reported the organosilane modification of halloysite nanotubes. Table-3 explains that organosilane modified HNTs (m-HNTs) that were fabricated with HNTs: silane ratio of 2.5:1 and 5:1 (w/v). The product was achieved by two methods. In Carli method, HNTs $(20 \mathrm{~g})$ was mixed in $96 \%$ ethyl alcohol $(120 \mathrm{ml})$ under strong stirring with subsequent addition of the organosilane and further lead to stirring for 2 hours. In the
Yuan method, moisture free toluene and HNTs $(20 \mathrm{~g})$ were mixed and then refluxed at continuous stirring in nitrogen for 20 hours at $120^{\circ} \mathrm{C}$. All modifiedHNTs models were obtained in a Buchner funnel with subsequent filtering and cleaning with 96 v. \% ethyl alcohol or moisture free toluene to seperate leftover organosilane. The modified-HNTs were parched under vacuum at $70^{\circ} \mathrm{C}$ overnight until a constant mass was obtained ${ }^{120}$.

Table-3: Synthesis route and m- HNTs sample IDs ${ }^{120}$

\begin{tabular}{|c|c|c|c|}
\hline Sample IDs & $\begin{array}{c}\text { Organosilane } \\
\text { reagent }\end{array}$ & $\begin{array}{c}\text { Synthesis } \\
\text { route }\end{array}$ & $\begin{array}{c}\text { Ratio (w/v) } \\
\text { HNTs:Organosilane }\end{array}$ \\
\hline modified-HNTs $\mathrm{C}_{8}$-E & $\mathrm{C}_{8}$ & $\begin{array}{c}\text { Ethanol- } \\
\text { Stirring }\end{array}$ & $5: 1$ \\
\hline modified -HNTs $\mathrm{C}_{8}-\mathrm{T}$ & $\mathrm{C}_{8}$ & $\begin{array}{c}\text { Toluene- } \\
\text { Refluxing }\end{array}$ & $5: 1$ \\
\hline modified -HNTs $\mathrm{C}_{18}-\mathrm{T}$ & $\mathrm{C}_{18}$ & $\begin{array}{c}\text { Toluene- } \\
\text { Refluxing }\end{array}$ & $5: 1$ \\
\hline modified -HNTs $2 \mathrm{C}_{18}-\mathrm{T}$ & $\mathrm{C}_{18}$ & $\begin{array}{c}\text { Toluene- } \\
\text { Refluxing }\end{array}$ & $25: 1$ \\
\hline
\end{tabular}

4.19 Preparation of chitosan-modified halloysite nanotubules

$\mathrm{Fu}$ et al. reported the modification of HNTs with chitosan. (1g) was mixed with $100 \mathrm{ml}$ of $2 \%$ wt. acetic acid solution under stirring until the chitosan was fully solubilized after that halloysite nanotubes powder (1g) was mixed to chitosan solution and dispersed under ultrasonic stirring for 30 minutes to obtain a uniform dispersion. The dispersion was constantly stirred for twelve hours at $60^{\circ} \mathrm{C}$. Subsequently, the dispersion was employed centrifugation to separate precipitates. The precipitated were initially soaked into sodium carbonate solution (1M) for 1 hour and then soaked in $100 \mathrm{ml}$ sodium borohydride solution $(0.2 \mathrm{M})$ for 5 hours at normal temperature. Again centrifugation and cleaning with distilled water for 3 times were performed to achieve chitosan modified HNTs. Then the chitosan-modified HNTs were parched for 48 hours at $60^{\circ} \mathrm{C}$ grounded to powder ${ }^{121}$. 
(a)

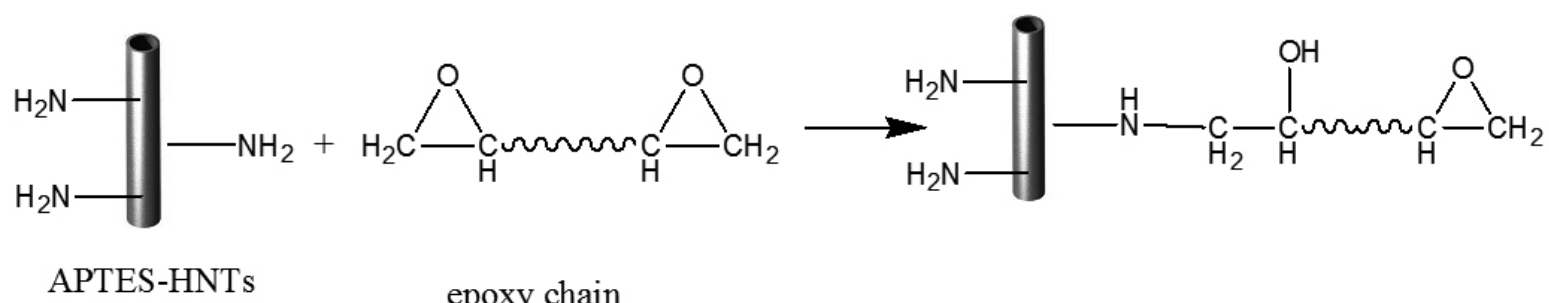

(b)<smiles>C(=C(C1CO1)[C@H]1CO1)[C@H]1CO1</smiles><smiles>NNCCCCCCCC1CO1</smiles>
amine hardener epoxy chain

DGEBA-HNTs $\downarrow$<smiles>OC(CNCCCCCCCCC1CO1)C(O)CC1CO1</smiles>

Fig- 23 APTES-HNTs and DGEBA-HNTs ${ }^{118}$

\subsection{Silane-treated HNTs}

In another study, Albdiry et al. modified HNTs with silanes. The dispersion of halloysite nanotubes in the polymer matrix can be improved by its modification with coupling agent such as vinyltrimethoxysilane $98 \%$ solution (VTMS, $\mathrm{C}_{5} \mathrm{H}_{12} \mathrm{O}_{3} \mathrm{Si}$ ) having molecular weight 148.23. HNTs were chemically treated with VTMS solution with a ratio (1:10). In a beaker, $100 \mathrm{~g}$ of halloysite nanotubes and $10 \mathrm{ml}$ of VTMS were mixed to an aqueous solution containing absolute ethyl alcohol $(500 \mathrm{ml})$, deionized water $(50 \mathrm{ml})$ and acetic acid $(2 \mathrm{ml})$ to keep $\mathrm{pH}$ in the range of 4.5-5.5. The solution was prepared using sol- ge process with stirring at a temperature of $60^{\circ} \mathrm{C}$ for 2 hours. The slurry was separated from water and at ambient temperature for 2 hours at $100^{\circ} \mathrm{C}$ for 8 hours till the moistness is entirely vaporized. After grinding mass is ready for use by passing through metal sieve ${ }^{122}$

\subsection{Modification of HNTs with dextran}

$\mathrm{Yu}$ et al. reported the modification of HNTs with dextran. Reaction for the modification are given in figure 24 showed two major steps for this modification ${ }^{123}$.

4.22 Halloysite modified with 1, 6- Hexa methylene diisocyanate (HDI)

$\mathrm{Yu}$ et al. reported that first the halloysite nanotubes should be dried at $400^{\circ} \mathrm{C}$ for 5 hours to remove the adsorbed water contents. Now halloysite $(1 \mathrm{~g})$ and acetone $(50 \mathrm{ml})$ were mixed and ultra-sonicated for 1 hour. After this diisocyanate $(2.7 \mathrm{~g})$ was poured into the resultant mixture then dibutyltin dilaurate $(0.1 \mathrm{~g})$ was added and the resultant mixture was refluxed at $70^{\circ} \mathrm{C}$ for 3 hours. The modified HNTs grafted with HDI (HNTs-HDI) was obtained by the centrifugation process and rinsed with acetone for four times. The mass was dried in a vacuum oven at $60^{\circ} \mathrm{C}$ for two nights ${ }^{123}$.

4.23 Dextran grafting on HNTs

$\mathrm{Yu}$ et al. reported that $4 \mathrm{~g}$ of modified halloysite and $8 \mathrm{~g}$ of dextran were taken into $100 \mathrm{ml}$ of DMSO and dibutyltin dilaurate $(0.1 \mathrm{~g})$ was poured into the mixture. The whole system was stirred at $80^{\circ} \mathrm{C}$ for 6 hours. Mass was obtained by centrifugation. Now the halloysite-dextran nanocomposites were dried under vacuum at $60^{\circ} \mathrm{C}$ for 48 hours ${ }^{123}$.

4.24 Synthesis of (polyethylene imine) PEI functionalized HNTs

Tian et al. reported the synthesis of PEI modified halloysite nanotubes. First, APTES-modified HNTs (APTES-HNTs) were synthesized. For the preparation of PEI-HNTs, APTES functionalized halloysite powder $(4 \mathrm{~g})$ was

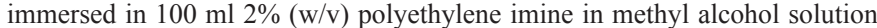
for 24 hours under strong stirring. After that, the mixture was immediately moved into $200 \mathrm{ml} \mathrm{1 \%}$ (w/v) glutaraldehyde solution for 30 minutes, followed by washing with ultra-pure water numerous times till the mixture became clear. The polyethylene imine -halloysite were obtained (PEI-HNTs) by drying under vacuum at $60^{\circ} \mathrm{C}^{124}$. In another study halloysite and PEI-modified halloysitefilled acrylonitrile butadiene styrene (ABS)/polypropylene blends and its composites using of dual compatibilizer were fabricated. The refinement in droplet-matrix structure, formation of $\beta$-form of PP crystals, increase in crystallinity of polypropylene (PP) phase, selective localization of polyethylene imine-modified HNTs and enhanced dispersal of polyethylene imine-modified HNTs in polypropylene (PP) phase were appeared in a significant enhancement in thermal stability, impact strength and tensile modulus of PEI-modified HNTs-incorporated 20/80 (wt/wt) ABS/PP blends using dual compatibilizer ${ }^{125}$

\subsection{Modifications for pro drug}

Multicavity HNTs were applied as carriers for silibinin and quercetin drug loadings and dilevery. The grafting of outer surface of HNTs were undertook via functionalized amphiphilic cyclodextrin. UV-vis spectroscopy was employed to study the drug release capacity of amphiphilic cyclodextrin functionalized halloysite at two different $\mathrm{pH}$ values. It was observed by biological assays that new complex shows anti-proliferative activity against human anaplastic thyroid cancer cell lines $8505 \mathrm{C}$. It was seen that synthesized multicavity system of the proper size is good for transportation drugs into the living cells ${ }^{126}$. 


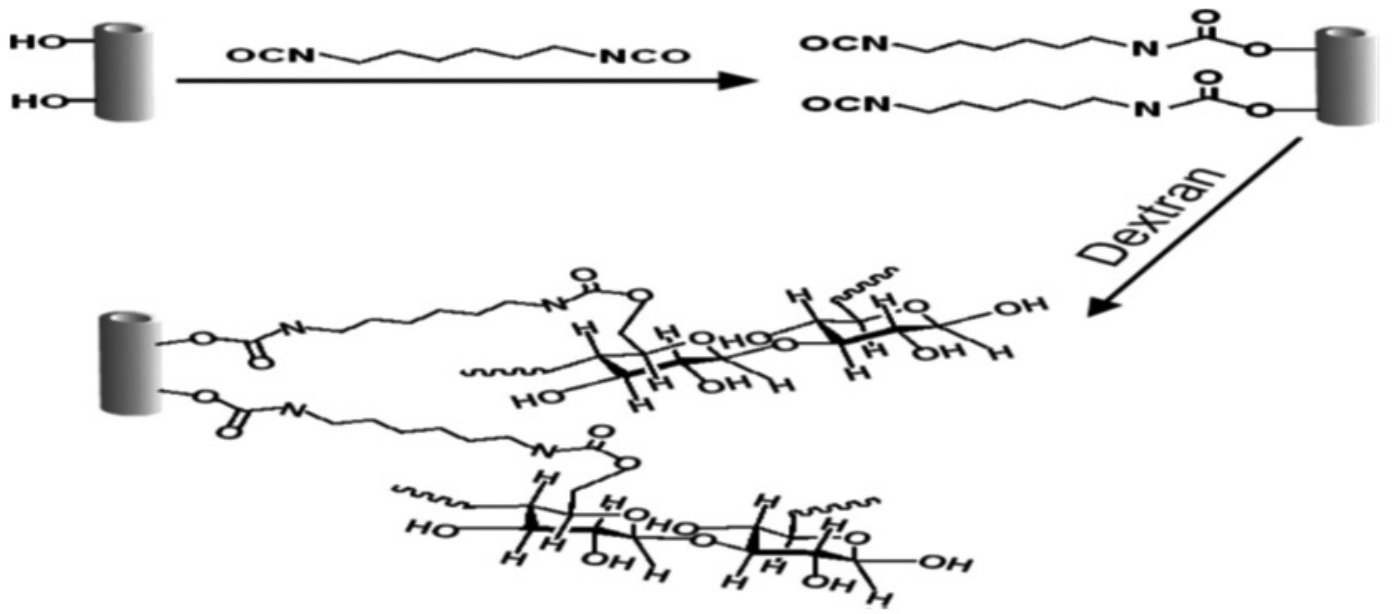

Fig- 24 Dextran modified HNTs ${ }^{123}$

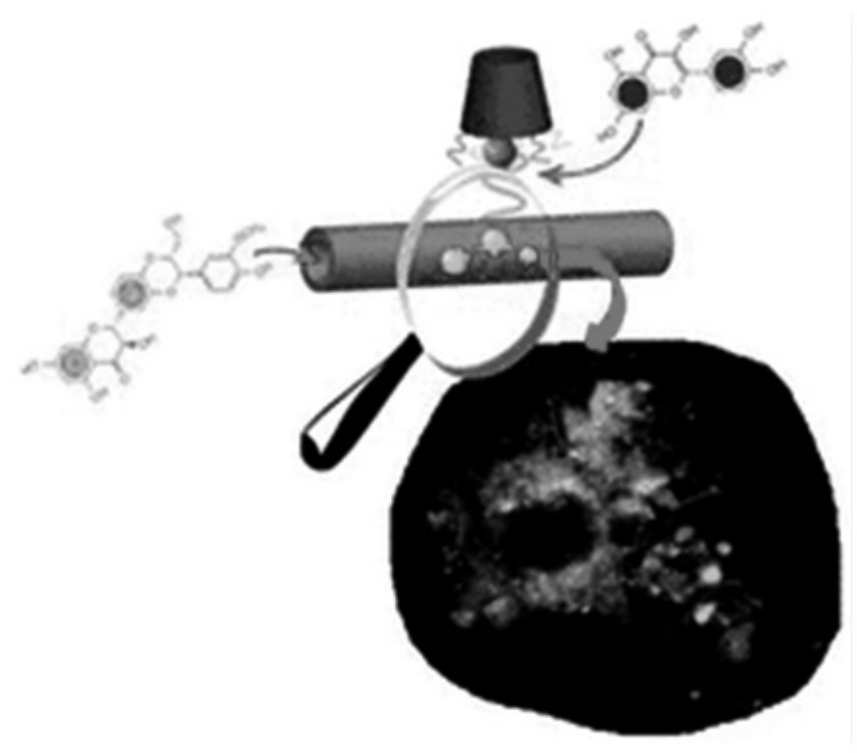

Fig- 25 Grafting of amphiphilic cyclodextrinonto the halloysite nanotube

In another study covalently functionalized HNTs was utilized as dual responsive nanocarriers for curcumin. Especially, they prepared halloysitecurcumin prodrug with the ability of controlled release of curcumin depending on $\mathrm{pH}$ conditions and intracellular glutathione. To get halloysite-curcumin prodrug HNTs was first functionalized with cystamine by disulphide linkages. After that curcumin molecules were chemically conjugated to amino end groups of HNTs through Schiff base formation. This is an efficient method to prepare HNTs based nanocarriers exhibiting controlled drug delivery ${ }^{127}$.

\section{FILLING OF HNTs}

A vial containing halloysite nanotubes mixture and a saturated solution of besieged molecules is held in reserve in a vacuum container and is repeatedly evacuated by using a vacuum pump. Slight twinkling produced in the suspension shows the elimination of air from the lumen of HNTs. Once the twinkling is clogged, the vessel is sealed for thirty minutes to acquire the equilibrium among the molecules of components. By the centrifugation, surplus dissolved molecules are detached from HNTs suspension and are washed. The whole procedure is repeated to confirm that the maximum quantity of the besieged molecules has been filled in HNTs. Halloysite nanotubes lumen can be loaded with required materials by using this simple loading procedure.

\section{CONCLUSION}

For the optimized properties of nanocomposites, it is to optimize the nanotube dispersion and stress transfer. The interfacial interaction between nanotubes and polymer must be carefully control. So, the functionalization of HNTs is particularly essential for processing and facilitating the properties of halloysite nanotubes-polymer composites. Modified nanotubes showed superior thermal-mechanical behavior in reported literature. Functionalization mends the dispersal and stress-strain transfer. Halloysite is idiosyncratic materials composed of a double layer of aluminium (Al), silicon $(\mathrm{Si})$, hydrogen $(\mathrm{H})$ and oxygen $(\mathrm{O})$ and are nontoxic. On the bases of surface area, and pore size, halloysite are of various grades. Therefore, halloysite can be considered as a promising nanomaterial for the preparation of different structural and functional materials. Modified halloysite was prepared by different modifying methods by various researchers to enhance dispersion and interfacial interactions in the polymer matrices. It seems that without modification, halloysite tend to exist in clusters and its uniform dispersion is difficult.

\section{REFERENCES}

1. J. H. Kirkman, Clay Minerals 12 (3), 199-216 (1977).

2. Y. Ye, H. Chen, J. Wu and L. Ye, Polymer 48 (21), 6426-6433 (2007)

3. E. Joussein, S. Petit, J. Churchman, B. Theng, D. Righi and B. Delvaux, Clay Minerals 40 (4), 383-426 (2005).

4. S. R. Levis and P. B. Deasy, International Journal of Pharmaceutics 243 (1-2), 125-134 (2002)

5. W. Jinhua, Z. Xiang, Z. Bing, Z. Yafei, Z. Rui, L. Jindun and C. Rongfeng, Desalination 259 (1-3), 22-28 (2010).

6. M. J. Saif and H. M. Asif, Journal of the Chilean Chemical Society 60 (2), 2949-2953 (2015)

7. R. Klimkiewicz and E. B. Drąg, Journal of Physics and Chemistry of Solids 65 (2-3), 459-464 (2004).

8. M. Alexandre and P. Dubois, Materials Science and Engineering: R: Reports 28 (1), 1-63 (2000).

9. Z. Shi, G. Xueping, S. Deying, Y. Zhou and D. Yan, Polymer 48 (26), 7516-7522 (2007)

10. J. S. Lim, I. Noda and S. S. Im, Polymer 48 (9), 2745-2754 (2007).

11. E. Joussein, S. Petit, J. Churchman, B. Theng, D. Righi and B. Delvaux, Clay Minerals 40 (4), 383-426 (2005).

12. K. Prashantha, H. Schmitt, M. F. Lacrampe and P. Krawczak, Composites Science and Technology 71 (16), 1859-1866 (2011).

13. S. Deng, J. Zhang and L. Ye, Composites Science and Technology 69 (14), 2497-2505 (2009).

14. Y. Tang, S. Deng, L. Ye, C. Yang, Q. Yuan, J. Zhang and C. Zhao, Composites Part A: Applied Science and Manufacturing 42 (4), 345-354 (2011).

15. C. Li, J. Liu, X. Qu, B. Guo and Z. Yang, Journal of applied polymer science 110 (6), 3638-3646 (2008) 
16. C. Liu, Y. Luo, Z. Jia, B. Zhong, S. Li, B. Guo and D. Jia, Express Polymer Letters 5 (7), 591-603 (2011).

17. J. Zhang, D. Zhang, A. Zhang, Z. Jia and D. Jia, Iran Polym J 22 (7), 501 510 (2013).

18. Y. Tang, L. Ye, S. Deng, C. Yang and W. Yuan, Materials \& Design 42 (0), 471-477 (2012).

19. J. Hári, Z. Dominkovics, E. Fekete and B. Pukánszky, Express Polym Lett 3 (11), 692-702 (2009)

20. K. Yang, Q. Yang, G. Li, Y. Sun and D. Feng, Materials Letters 60 (6), 805-809 (2006)

21. U. A. Handge, K. Hedicke-Höchstötter and V. Altstädt, Polymer 51 (12), 2690-2699 (2010).

22. W. Bascom, R. Cottington, R. Jones and P. Peyser, Journal of Applied Polymer Science 19 (9), 2545-2562 (1975).

23. T. Hsieh, A. Kinloch, K. Masania, A. Taylor and S. Sprenger, Polymer 51 (26), 6284-6294 (2010).

24. A. Kinloch and A. Taylor, J Mater Sci Lett 22 (20), 1439-1441 (2003)

25. F. Hussain, M. Hojjati, M. Okamoto and R. E. Gorga, Journal of composite materials 40 (17), 1511-1575 (2006)

26. A. C. Garg and Y.-W. Mai, Composites Science and Technology 31 (3), 179-223 (1988).

27. F. H. Gojny, M. H. Wichmann, B. Fiedler and K. Schulte, Composites Science and Technology 65 (15), 2300-2313 (2005).

28. K. K. Maniar, Polymer-Plastics Technology and Engineering 43 (2), 427 443 (2004).

29. P. Kubade and P. Tambe, Composite Interfaces 23 (5), 433-451 (2016).

30. S. M. Saheb, P. Tambe and M. Malathi, Journal of Thermoplastic Composite Materials, 0892705717697775 (2017).

31. P. Tambe and M. Malathi, International Journal of Chemical Sciences 15 (1) (2017).

32. V. Vergaro, E. Abdullayev, Y. M. Lvov, A. Zeitoun, R. Cingolani, R Rinaldi and S. Leporatti, Biomacromolecules 11 (3), 820-826 (2010).

33. D. G. Shchukin, G. B. Sukhorukov, R. R. Price and Y. M. Lvov, Small 1 (5), 510-513 (2005)

34. M. Du, B. Guo and D. Jia, European Polymer Journal 42 (6), 1362-1369 (2006).

35. L. Sun, R. F. Gibson, F. Gordaninejad and J. Suhr, Composites Science and Technology 69 (14), 2392-2409 (2009).

36. E. Abdullayev, R. Price, D. Shchukin and Y. Lvov, ACS applied materials \& interfaces 1 (7), 1437-1443 (2009).

37. D. W. Rachel, V. B. Dmitry and C. W. Frank, Nanotechnology 23 (6) 065705 (2012).

38. H. S. Mohtashim and E. G. Kurt, Nanotechnology 19 (7), 075604 (2008)

39. R. Qi, X. Cao, M. Shen, R. Guo, J. Yu and X. Shi, Journal of Biomaterials Science, Polymer Edition 23 (1-4), 299-313 (2012).

40. B. Lecouvet, J. Horion, C. D'Haese, C. Bailly and B. Nysten, Nanotechnology 24 (10), 105704 (2013).

41. D. Lu, H. Chen, J. Wu and C. M. Chan, Journal of nanoscience and nanotechnology 11 (9), 7789-7793 (2011).

42. L. Guimaraes, A. N. Enyashin, G. Seifert and H. A. Duarte, The Journal of Physical Chemistry C 114 (26), 11358-11363 (2010).

43. M. Liu, B. Guo, M. Du, X. Cai and D. Jia, Nanotechnology 18 (45), 455703 (2007).

44. P. Pasbakhsh, G. J. Churchman and J. L. Keeling, Applied Clay Science 74, 47-57 (2013).

45. A. Alhuthali and I. Low, Journal of Materials Science 48 (12), 4260-4273 (2013).

46. B. G. R. Price, Y. Lvov, R, Journal of microencapsulation 18 (6), 713-722 (2001).

47. M. Du, B. Guo, J. Wan, Q. Zou and D. Jia, Journal of polymer research 17 (1), 109-118 (2010)

48. Z. Jia, Y. Luo, B. Guo, B. Yang, M. Du and D. Jia, Polymer-Plastics Technology and Engineering 48 (6), 607-613 (2009).

49. H. Ismail, P. Pasbakhsh, M. Fauzi and A. Abu Bakar, Polymer Testing 27 (7), 841-850 (2008)

50. H. Ismail, S. Salleh and Z. Ahmad, Materials \& Design 50, 790-797 (2013).

51. X.-L. Xie, Y.-W. Mai and X.-P. Zhou, Materials Science and Engineering: R: Reports 49 (4), 89-112 (2005)

52. M. Du, B. Guo and D. Jia, Polymer International 59 (5), 574-582 (2010).

53. M. Du, B. Guo and D. Jia, European Polymer Journal 42 (6), 1362-1369 (2006).

54. H. Qin, S. Zhang, C. Zhao, G. Hu and M. Yang, Polymer 46 (19), 8386-
8395 (2005).

55. P. Wei, G. Tian, H. Yu and Y. Qian, Polymer Degradation and Stability 98 (5), 1022-1029 (2013).

56. W. O. Yah, A. Takahara and Y. M. Lvov, Journal of the American Chemical Society 134 (3), 1853-1859 (2012).

57. Y. Lvov, R. Price, B. Gaber and I. Ichinose, Colloids and Surfaces A Physicochemical and Engineering Aspects 198, 375-382 (2002).

58. M. Liu, Y. Zhang, C. Wu, S. Xiong and C. Zhou, International journal of biological macromolecules 51 (4), 566-575 (2012).

59. D. Solomon, Clays Clay Miner 16, 31-39 (1968).

60. M. Liu, B. Guo, Q. Zou, M. Du and D. Jia, Nanotechnology 19 (20), 205709 (2008)

61. A. Wang, F. Kang, Z. Huang, Z. Guo and X. Chuan, Microporous and Mesoporous Materials 108 (1), 318-324 (2008).

62. I. Wilson, Clay Minerals 39 (1), 1-15 (2004).

63. I. Wilson, H. D. S. Santos and P. D. S. Santos, Clay minerals 41 (3), $697-$ 716 (2006).

64. K. Qiu and A. N. Netravali, Polymer Composites 34 (5), 799-809 (2013).

65. L. Ames, Clays and Clay Minerals 6, 378-385 (1957).

66. F. J. García, S. García Rodríguez, A. Kalytta and A. Reller, Zeitschrift für anorganische und allgemeine Chemie 635 (4 $\square 5$ ), 790-795 (2009).

67. M. Poikelispää, A. Das, W. Dierkes and J. Vuorinen, Journal of Applied Polymer Science 127 (6), 4688-4696 (2013).

68. R. Li, Z. Hu, S. Zhang, Z. Li and X. Chang, International Journal of Environmental Analytical Chemistry 93 (7), $767-779$ (2011).

69. B. Mu, M. Zhao and P. Liu, J Nanopart Res 10 (5), 831-838 (2008).

70. P. Pasbakhsh, H. K. How and C. S. Piao.

71. M. Poikelispaa, A. Das, W. Dierkes and J. Vuorinen, (2011).

72. P. Yuan, P. D. Southon, Z. Liu, M. E. Green, J. M. Hook, S. J. Antill and C. J. Kepert, The Journal of Physical Chemistry C 112 (40), 15742-15751 (2008)

73. M. Liu, B. Guo, M. Du, Y. Lei and D. Jia, Journal of Polymer Research 15 (3), 205-212 (2008)

74. M. J. Saif, M. Asif, M. Naveed, K. M. Zia, W.-u. Zaman, M. K. Khosa and M. A. Jamal, Polish Journal of Chemical Technology 18 (1), 133-135 (2016)

75. C. Li, J. Liu, X. Qu and Z. Yang, Journal of applied polymer science 112 (5), 2647-2655 (2009)

76. P. Yuan, P. D. Southon, Z. Liu, M. E. R. Green, J. M. Hook, S. J. Antill and C. J. Kepert, The Journal of Physical Chemistry C 112 (40), 15742 15751 (2008)

77. P. Luo, J.-s. Zhang, B. Zhang, J.-h. Wang, Y.-f. Zhao and J.-d. Liu, Industrial \& Engineering Chemistry Research 50 (17), 10246-10252 (2011)

78. B. Guo, Q. Zou, Y. Lei and D. Jia, Polymer journal 41 (10), 835-842 (2009).

79. J. Zhang, D. Zhang, A. Zhang, Z. Jia and D. Jia, Journal of Reinforced Plastics and Composites 32 (10), 713-725 (2013)

80. L.-P. Wang, Y.-P. Wang, X.-W. Pei and B. Peng, Reactive and Functional Polymers 68 (2), 649-655 (2008)

81. Y. Joo, Y. Jeon, S. U. Lee, J. H. Sim, J. Ryu, S. Lee, H. Lee and D. Sohn, The Journal of Physical Chemistry C 116 (34), 18230-18235 (2012).

82. B. Yin and M. Hakkarainen, Journal of Materials Chemistry 21 (24), 8670-8677 (2011)

83. C. Liu, Y. Luo, Z. Jia, B. Zhong, S. Li, B. Guo and D. Jia, Express Polym Lett 5 (7), 591-603 (2011)

84. W. O. Yah, H. Xu, H. Soejima, W. Ma, Y. Lvov and A. Takahara, Journal of the American Chemical Society 134 (29), 12134-12137 (2012).

85. Y. Liu, Q. Cai, H. Li and J. Zhang, Journal of Applied Polymer Science 128 (1), 517-522 (2013)

86. J. L. Guimarães, P. Peralta-Zamora and F. Wypych, Journal of colloid and interface science 206 (1), 281-287 (1998).

87. H. Jing, Y. Higaki, W. Ma, H. Wu, W. O. Yah, H. Otsuka, Y. M. Lvov and A. Takahara, Chemistry Letters 42 (2), 121-123 (2013).

88. V. Khunova, J. Kristóf, I. Kelnar and J. Dybal, Express Polymer Letters 7 (5) (2013)

89. W. Xu, B. Luo, W. Wen, W. Xie, X. Wang, M. Liu and C. Zhou, Journal of Applied Polymer Science 132 (7) (2015).

90. A.-B. Zhang, L. Pan, H.-Y. Zhang, S.-T. Liu, Y. Ye, M-S. Xia and XG. Chen, Colloids and Surfaces A: Physicochemical and Engineering Aspects 396, 182-188 (2012).

91. H. Lun, J. Ouyang and H. Yang, Physics and Chemistry of Minerals 41 (4), 281-288 (2014). 
92. G. Cavallaro, G. Lazzara, S. Milioto, G. Palmisano and F. Parisi, Journal of colloid and interface science 417, 66-71 (2014).

93. G. Cavallaro, G. Lazzara, S. Milioto and F. Parisi, Langmuir 31 (27), $7472-7478$ (2015)

94. G. Cavallaro, G. Lazzara, S. Milioto, F. Parisi and V. Sanzillo, ACS applied materials \& interfaces 6 (1), 606-612 (2013).

95. G. Cavallaro, G. Lazzara and S. Milioto, The Journal of Physical Chemistry C 116 (41), 21932-21938 (2012).

96. J. Deng and L. Ye, presented at the Proc. 17th Int. Conf. on 'Composite materials', Edinburgh, UK, 2009 (unpublished).

97. D. Solomon and M. Rosser, Journal of Applied Polymer Science 9 (4), 1261-1271 (1965)

98. M. Liu, B. Guo, M. Du and D. Jia, Polymer journal 40 (11), 1087-1093 (2008).

99. M. Du, B. Guo, M. Liu and D. Jia, Polymer journal 39 (3), 208-212 (2007).

100. M. Du, B. Guo, M. Liu, X. Cai and D. Jia, Physica B: Condensed Matter 405 (2), 655-662 (2010)

101. H. Kelly, P. Deasy, E. Ziaka and N. Claffey, International journal of pharmaceutics 274 (1), 167-183 (2004).

102. Y. Lvov, A. Aerov and R. Fakhrullin, Advances in colloid and interface science (2013).

103. M. H. Shamsi and K. E. Geckeler, Nanotechnology 19 (7), 075604 (2008).

104. Z. Lu, S. Eadula, Z. Zheng, K. Xu, G. Grozdits and Y. Lvov, Colloids and Surfaces A: Physicochemical and Engineering Aspects 292 (1), 56-62 (2007).

105. V. Bertolino, G. Cavallaro, G. Lazzara, S. Milioto and F. Parisi, Langmuir 33 (13), 3317-3323 (2017)

106. V. Bertolino, G. Cavallaro, G. Lazzara, M. Merli, S. Milioto, F. Parisi and L. Sciascia, Industrial \& Engineering Chemistry Research 55 (27), 73737380 (2016).

107. E. Abdullayev, A. Joshi, W. Wei, Y. Zhao and Y. Lvov, ACS nano 6 (8), 7216-7226 (2012).

108. R. D. White, D. V. Bavykin and F. C. Walsh, Nanotechnology 23 (6), $065705(2012)$

109. Y. Joo, J. H. Sim, Y. Jeon, S. U. Lee and D. Sohn, Chemical Communications 49 (40), 4519-4521 (2013).

110. C. Chao, J. Liu, J. Wang, Y. Zhang, B. Zhang, Y. Zhang, X. Xiang and R. Chen, ACS applied materials \& interfaces 5 (21), 10559-10564 (2013).

111. J. Ling, Z. Chao, W. Junchao, T. Wengweei, P. Jisheng, C. Yiwang and L. Tianxi, CHEMICAL RESEARCH IN CHINESE UNIVERSITIES 30 (6), 971-977 (2014).

112. R. L. Frost, J. Kristof, E. Mako and J. T. Kloprogge, American Mineralogist 85 (11-12), 1735-1743 (2000).

113. M. Massaro, S. Riela, G. Cavallaro, M. Gruttadauria, S. Milioto, R. Noto and G. Lazzara, Journal of Organometallic Chemistry 749, 410-415 (2014).

114. B. Szczepanik, P. Słomkiewicz, M. Garnuszek, K. Czech, D. Banaś, A. Kubala-Kukuś and I. Stabrawa, Journal of Molecular Structure 1084, 16$22(2015)$

115. S. Zeng, C. Reyes, J. Liu, P. A. Rodgers, S. H. Wentworth and L. Sun, Polymer 55 (25), 6519-6528 (2014).

116. H. Hemmatpour, V. Haddadi-Asl and H. Roghani-Mamaqani, Polymer 65, 143-153 (2015)

117. Q. He, D. Yang, X. Deng, Q. Wu, R. Li, Y. Zhai and L. Zhang, Water research 47 (12), 3976-3983 (2013).

118. V. Vahedi and P. Pasbakhsh, Polymer Testing 39, 101-114 (2014).

119. Y. He, W. Kong, W. Wang, T. Liu, Y. Liu, Q. Gong and J. Gao, Carbohydrate Polymers 87 (4), 2706-2711 (2012).

120. E. Bischoff, T. Daitx, D. A. Simon, H. S. Schrekker, S. A. Liberman and R. S. Mauler, Applied Clay Science 112, 68-74 (2015).

121. H. Fu, Y. Wang, W. Chen and J. Xiao, Applied Surface Science 346, 372378 (2015).

122. M. Albdiry, H. Ku and B. Yousif, Engineering Failure Analysis 35, 718725 (2013).

123. H. Yu, Y. Zhang, X. Sun, J. Liu and H. Zhang, Chemical Engineering Journal 237, 322-328 (2014).

124. X. Tian, W. Wang, Y. Wang, S. Komarneni and C. Yang, Microporous and Mesoporous Materials 207, 46-52 (2015).

125. P. Kubade and P. Tambe, Composite Interfaces 24 (5), 469-487 (2017).

126. M. Massaro, S. Piana, C. Colletti, R. Noto, S. Riela, C. Baiamonte, C. Giordano, G. Pizzolanti, G. Cavallaro and S. Milioto, Journal of Materials
Chemistry B 3 (19), 4074-4081 (2015).

127. M. Massaro, R. Amorati, G. Cavallaro, S. Guernelli, G. Lazzara, S. Milioto, R. Noto, P. Poma and S. Riela, Colloids and Surfaces B Biointerfaces 140, 505-513 (2016).

128. Nanoclay, www.nanoclya.com

129. Nano by Nature, (Bernhardt Fudmya Design Group), www.bfdg.com (2011).

130. M. J. Saif, M. Naveed, K. M. Zia and M. Asif, Radiation Physics and Chemistry 127, 115-121 (2016).

131. F. Wang, X. Zhang, Y. Ma and W. Yang, Applied Surface Science, 427, 1038-1045 (2018)

132. Z. Long, Y. Wu, H. Y. Gao, Y. F. Li, R. He, and M. Liu, Bioconjugate chemistry, (2018)

133. S. Cataldo, G. Lazzara, M. Massaro, N. Muratore, A. Pettignano, and S. Riela, Applied Clay Science, 156, 87-95 (2018).

134. D. Garcia-Garcia, D. Garcia-Sanoguera, V. Fombuena, J. Lopez-Martinez and R. Balart, Applied Clay Science, 162, 487-498 (2018).

135. W. Ma, H. Wu, Y. Higaki and A. Takahara, The Chemical Record, (2018).

136. S. Sadjadi and M. Atai, Applied Clay Science, 153, 78-89 (2018).

137. M. D. F. V. Marques, J. L. da Silva Rosa and M. C. V. da Silva, Polymer Bulletin, 74(7), 2447-2464 (2017).

138. S. Padhi, P. G. R. Achary and N. C. Nayak, Journal of Polymer Engineering, 38(3), 271-279 (2018).

139. R. Kamble, M. Ghag, S. Gaikawad and B. K. Panda, Journal of Advanced Scientific Research, 3(2) 25-29 (2012).

140. W. O. Yah, A. Takahara and Y. M. Lvov, Journal of the American Chemical Society, 134(3), 1853-1859 (2012)

141. G. Lazzara, G. Cavallaro, A. Panchal, R. Fakhrullin, A. Stavitskaya, V. Vinokurov and Y. Lvov, Current Opinion in Colloid \& Interface Science, 35, 42-50 (2018).

142. E. G. Bediako, E. Nyankson, D. Dodoo-Arhin, B. Agyei-Tuffour, D. Łukowiec, B. Tomiczek, A. Yaya and J. K. Efavi, Heliyon, 4(7), 689 (2018).

143. L. Fu, H. Yang, A. Tang and Y. Hu, Nano Research, 10(8), 2782-2799 (2017).

144. N. Sabbagh, A. Akbari, N. Arsalani, B. Eftekhari-Sis and H. Hamishekar, Applied Clay Science, 148, 48-55 (2017)

145. C. S. Ana, F. Caroline, V. Francisco, J. R. Antonio, P. Abhishek, L. Yuri and A. Anshul, Advances in colloid and interface science, 257, 58-70 (2018). 